\title{
High-density Lipoprotein Cholesterol Is Negatively Correlated with Bone Mineral Density and Has Potential Predictive Value for Bone Loss
}

Yuchen Tang ${ }^{1,2,3+}$, Shenghong Wang ${ }^{1,2,3+}$, Qiong Yi ${ }^{1,2,3}$, Yayi Xia ${ }^{1,2,3}$ and Bin Geng ${ }^{1,2,3^{*}}$

\begin{abstract}
Background: Many studies have shown that lipids play important roles in bone metabolism. However, the association between high-density lipoprotein cholesterol (HDL-C) and bone mineral density (BMD) is unclear. Therefore, this study aimed to investigate the linear or nonlinear relation between $\mathrm{HDL}-\mathrm{C}$ levels and BMD and addressed whether the HDL$C$ levels had the potential values for predicting the risk of osteoporosis or osteopenia.

Methods: Two researchers independently extracted all information from the National Health and Nutrition Examination Survey (NHANES) database. Participants over 20 years of age with available HDL-C and BMD data were enrolled in the final analysis. The linear relationship between $\mathrm{HDL}-\mathrm{C}$ levels and BMD was assessed using multivariate linear regression models. Moreover, the nonlinear relationship was also characterized by fitted smoothing curves and generalized additive models. In addition, the odds ratio $(\mathrm{OR})$ for osteopenia and osteoporosis was evaluated with multiple logistic regression models.

Results: The weighted multivariable linear regression models demonstrated that HDL-C levels displayed an inverse association with BMD, especially among females and subjects aged 30 to 39 or 50 to 59 . Moreover, the nonlinear relationship characterized by smooth curve fittings and generalized additive models suggested that (i) HDL-C levels displayed an inverted U-shaped relationship with BMD among women 30 to 39 or over 60 years of age; (ii) HDL-C levels exhibited a U-shaped association with BMD among women 20 to 29 or 50 to 59 years of age. In addition, females with high HDL levels (62-139 mg/dL) had an increased risk of osteopenia or osteoporosis.

Conclusion: This study demonstrated that HDL-C levels exhibit an inverse correlation with BMD. Especially in females, clinicians need to be alert to patients with high HDL-C levels, which may indicate an increased risk of osteoporosis or osteopenia. For these patients, close monitoring of BMD and early intervention may be necessary.
\end{abstract}

Keywords: Bone mineral density, High-density lipoprotein cholesterol, Osteoporosis, Osteopenia

\footnotetext{
* Correspondence: cxxxf@foxmail.com

†Yuchen Tang and Shenghong Wang contributed equally to this work. 'Department of Orthopaedics, Lanzhou University Second Hospital, \#82 Cuiyingmen, Lanzhou, Gansu, People's Republic of China 730000 ${ }^{2}$ Orthopaedics Key Laboratory of Gansu Province, Lanzhou, Gansu, China Full list of author information is available at the end of the article
} permission directly from the copyright holder. To view a copy of this licence, visit http://creativecommons.org/licenses/by/4.0/ The Creative Commons Public Domain Dedication waiver (http://creativecommons.org/publicdomain/zero/1.0/) applies to the data made available in this article, unless otherwise stated in a credit line to the data. 


\section{Background}

Lipids play critical roles in physiopathology and include a variety of substances. High-density lipoprotein cholesterol (HDL-C) is a ubiquitous molecule, and one type of cholesterol is contained in or bound to high-density lipoprotein (HDL) [1]. HDL-C is believed to have beneficial impacts on human health, and high HDL-C levels are considered to be better for preventing cardiovascular disease over a long time [2, 3]. For instance, Gordon et al. reported an independent inverse association between HDL-C levels and the rate of coronary artery disease [4]. Rosenson et al. observed that statin treatment, which can increase HDL-C levels, was beneficial in cardiovascular disease reduction [5]. However, over the past few years, different opinions have been presented. Madsen et al. reported that adults with extremely high HDL cholesterol levels (men: $\geq 116 \mathrm{mg} / \mathrm{dL}$; women: $\geq 135$ $\mathrm{mg} / \mathrm{dL}$ ) paradoxically have high all-cause mortality [6]. Hamer et al. observed that HDL-C levels and mortality presented a U-shaped relationship in participants in a large sample, demonstrating that subjects with high levels of HDL-C also had increased mortality [7]. These findings may indicate that researchers should reconsider the perspective on HDL-C.

Osteoporosis is a high-incidence chronic disease described as reduced bone mineral density (BMD) [8]. According to the International Osteoporosis Foundation, one-third of women and one-fifth of men over 50 years of age have osteoporosis or osteopenia and are at risk for osteoporotic fracture [9]. Simultaneously, as the population ages and grows, the prevalence of osteoporosis continues to rise [10]. At present, apart from genetic factors, age, or sex, the impact of other factors, such as lipid metabolism or lifestyle, on bone metabolism has recently attracted considerable concern [11-13]. Meanwhile, researchers hope to discover novel modalities for osteoporosis prevention and treatment.

At present, numerous studies have shown that lipids play important roles in bone metabolism [14-16]. For example, Li et al. demonstrated that statin drug treatment can increase BMD by lowering low-density lipoprotein cholesterol (LDL-C) levels [15]. In addition, Zheng et al. found that statins can increase total body $\mathrm{BMD}$, and this effect was partly associated with lowering of LDL-C [16]. Moreover, it is uncertain and controversial whether HDL-C levels are correlated with BMD. There is some evidence that HDL-C levels are elevated in postmenopausal women and negatively associated with BMD. Maghbooli et al. found that HDL-C exhibited an inverse correlation with BMD in postmenopausal Iranian women with vitamin D deficiency [17]. Zhang et al. observed that HDL-C displayed a negative correlation with lumbar spine BMD in Chinese women [18]. Conversely, Cui et al. suggested that there was no association between HDL-C levels and BMD values at any sites in pre- and postmenopausal subjects [19]. Apart from the above, Jeong et al. observed that HDL-C exhibited a positive association with BMD in Korean postmenopausal women [20]. The conclusions of these studies remain controversial. Therefore, it is worth exploring the relation of HDL-C levels and BMD and determining whether HDL-C levels have potential value for predicting the risk of osteoporosis or osteopenia, which may provide a novel theoretical basis for understanding the aetiology of osteoporosis and developing treatments.

Accordingly, this study enrolled adults over 20 years of age and collected related information from the National Health and Nutrition Examination Survey (NHANES) database to explore the linear or nonlinear relationship between HDL-C and BMD and to investigate whether HDL-C levels have potential value for predicting the risk of osteoporosis or osteopenia.

\section{Materials and methods \\ Study design and population}

The NHANES database was compiled by the Centers for Disease Control, United States. The NHANES database collects and stores information on the health and nutritional status of American residents and is updated each year. The present study was a cross-sectional study. Two researchers (YT and SW) independently extracted data from NHANES 2005-2010 [21-23], and a third researcher (BG) regularly cross-checked the data collected. The ethics review board of the National Center for Health Statistics approved the study, and each participant signed a written informed consent form. Detailed information on the ethics application and written informed consent are provided on the NHANES website [24-26].

\section{Data collection}

Two researchers (YT and SW) independently extracted the following information:

1. Demographic data [age, gender, race/ethnicity, education level, and income to poverty ratio]

2. Examination data [BMD of femoral regions (total femur; femur neck; trochanter; intertrochanter) and the lumbar (L) spine (total spine; L1; L2; L3; L4)]

3. Laboratory data [HDL-C level $(\mathrm{mg} / \mathrm{dL})$, alanine aminotransferase (ALT) (U/L), aspartate aminotransferase (AST) (U/L), cholesterol level $(\mathrm{mg} / \mathrm{dL})$, total calcium $(\mathrm{mg} / \mathrm{dL})$, and C-reactive protein $(\mathrm{mg} / \mathrm{dL})]$

4. Questionnaire data [alcohol consumption status (had at least 12 alcohol drinks in the past one year), smoking status (smoked at least 100 cigarettes in 
life), BMI (derived from height and weight); diabetes (has a doctor told you that you have diabetes), and hypertension (ever been told you have high blood pressure)]

5. Weight value [According to the rules of the weight value selection provided on the NHANES website [27], "Full Sample Two-Year Mobile Examination Center Exam Weight (WTMEC2YR)" was selected to represent the weight value. The final weight value used for analysis was equal to one-third of the "Full Sample Two-Year Mobile Examination Center Exam Weight" due to combining three two-year cycles of the continuous NHANES]

\section{Inclusion and exclusion criteria}

The inclusion criteria were: (1) participants over or equal to 20 years of age, and (2) participants with available BMD and HDL-C data. The exclusion criteria were as follows: (1) subjects with cancer or malignancy (have doctors told you had cancer or a malignancy?); (2) subjects who used female hormones (ever used female hormones, such as oestrogen or progesterone?); and (3) subjects missing other variables data (data missing, answered "do not know" and refused to answer were considered missing data) were excluded.

\section{Measurement of HDL-C levels}

Briefly, based on the information provided on the NHANES website, the HDL-C measurement was performed at Lipid Laboratory, Johns Hopkins. Serum was collected for detection of HDL-C. Apolipoprotein-B (apoB)-containing lipoproteins were removed by reaction with blocking reagents and rendering them nonreactive with enzymatic cholesterol reagents under the assay conditions. HDL-C levels were measured using polyethylene glycol-coupled cholesteryl esterase, cholesterol oxidase, and sulfated alpha-cyclodextrin in the presence of $\mathrm{Mg}^{2+}$. Detailed information about the measurement of HDL-C is accessible on the NHANES website [28].

\section{Evaluation of BMD}

BMD was evaluated using dual energy X-ray absorptiometry (DXA) scans. The sites of assessment included femoral regions (total femur; femur neck; trochanter; intertrochanter) and the lumbar spine (total spine; L1; L2; L3; L4). Health technologists who were certified radiology technologists conducted the DXA scans using a Hologic QDR 4500A instrument (Hologic, Inc., Bedford, MA, USA) and Apex software version 3.2. Further details of the DXA examination protocol are described in the Body Composition Procedures Manual provided on the NHANES website [29].

\section{Osteopenia and osteoporosis}

According to a study by Looker et al. [30], the BMD reference value was the mean femoral BMD of nonHispanic white men and women aged 20 to 29 years from the NHANES III database. Osteopenia was defined as a BMD value in any femoral region between -1 and -2.5 SD of the reference value, and osteoporosis was defined as a BMD value in any femoral region lower than $-2.5 \mathrm{SD}$ of the reference value. The specific values are presented in Supplementary Table S1.

\section{Statistical analysis}

The baseline characteristics of all participants involved in the final analysis are described by the mean (continuity variable) or proportion (categorical variable). The linear relationship between HDL-C and BMD was assessed through weighted multivariate linear regression models. Subgroup analysis using multivariate linear regression models was performed to evaluate the linear relationship between HDL-C and BMD in diverse populations by stratifying age and sex. Moreover, the nonlinear relationship between HDL-C and BMD was characterized by smooth curve fittings and generalized additive models. The inflection point (if it existed) was calculated by employing two-piecewise linear regression models using a recursive algorithm. In addition, the odds ratio (OR) for osteopenia and osteoporosis was evaluated via multiple logistic regression analyses. $P$ values less than 0.05 were defined as significant. All analyses were performed using R software, v.4.0.3 (Vienna, Austria: R Foundation for Statistical Computing, 2016) and EmpowerStats (version: 2.0. X\&Y Solutions, Inc, Boston, MA. http://www. empowerstats. com). The frequency distribution graph of HDL-C was generated using Origin (version: 2021b. https://www.originlab.com/).

\section{Results}

\section{Participant selection and baseline characteristics}

The information of 31,034 participants was extracted from the NHANES database 2005-2010. (i) Subjects without BMD data were excluded ( $n=14344$ ); (ii) subjects without HDL-C data were excluded ( $n=1080)$; (iii) subjects below 20 years of age were excluded $(n=5516)$; (iv) subjects with cancer, malignancy or female hormone use were excluded ( $n=1576)$; and (v) subjects with missing values for other variables were excluded $(n=$ 1263, education level: 8, income to poverty ratio: 600 , BMI: 244, smoking status: 1, drinking status: 349, hypertension: 8, diabetes: 4, ALT: 45, AST: 1, cholesterol: 1, C-reactive protein: 2). After that, 7,255 participants were enrolled in the final analysis. A flow chart of participant selection is shown in Fig. 1.

Overall, the participants' mean age was $41.74 \pm 14.25$ years, and most were males (56.93\%) and non-Hispanic 


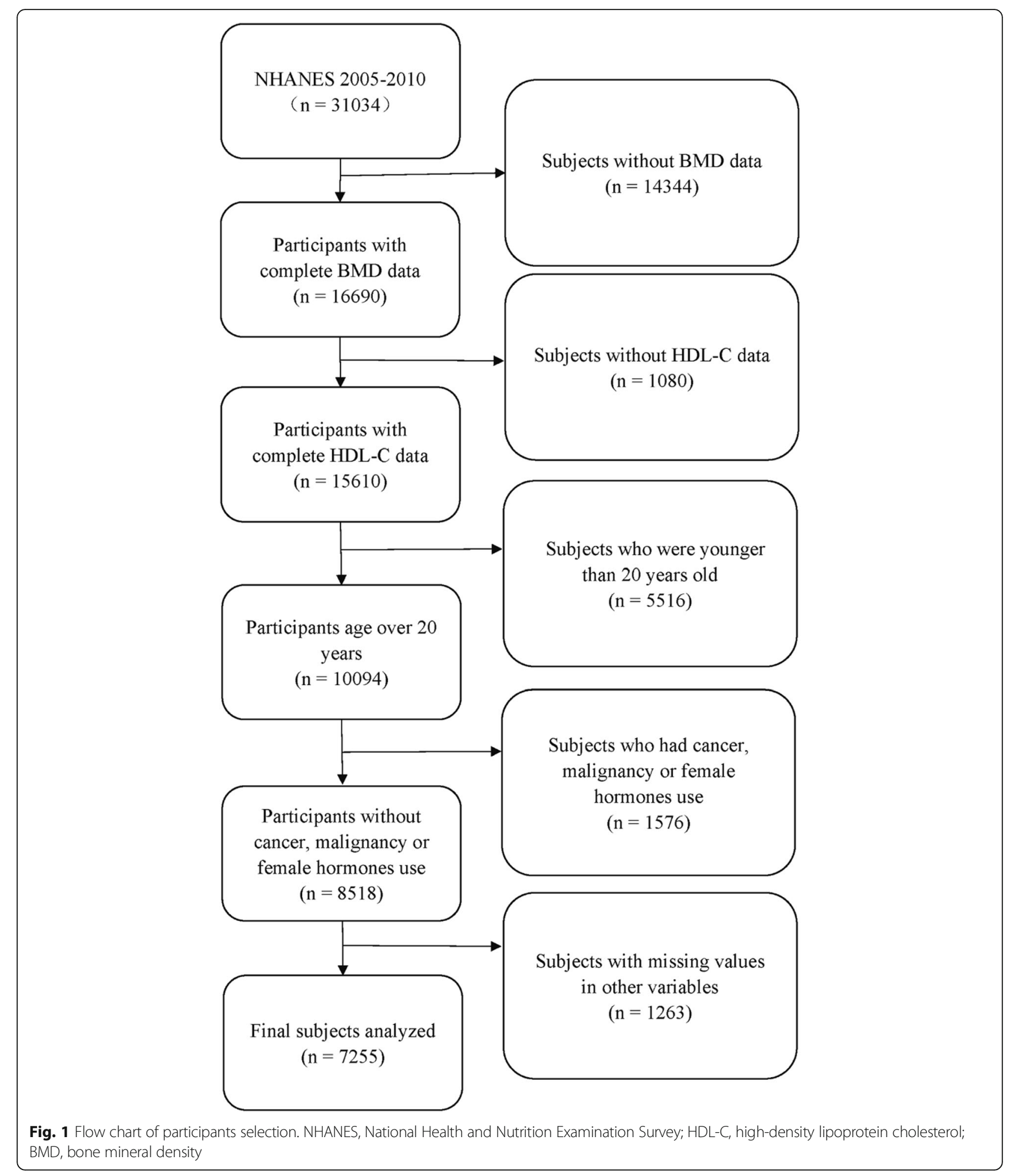

whites (69.43\%). The majority of individuals had an above high school education level (59.85\%) and a mean income to poverty ratio of $3.10 \pm 1.63$. Obesity (BMI $\geq$ 30), smoking (smoking at least 100 cigarettes in life), drinking (consuming at least 12 alcohol drinks past one year), hypertension, and diabetes accounted for $25.83 \%$, $46.31 \%, 79.20 \%, 22.18 \%$, and $5.38 \%$, respectively. In addition, the mean ALT, AST, cholesterol, total calcium, and C-reactive protein levels were $26.48 \pm 18.83,25.75 \pm$ 14.10, $9.46 \pm 0.35,196.71 \pm 40.39$, and $0.33 \pm 0.68$, 

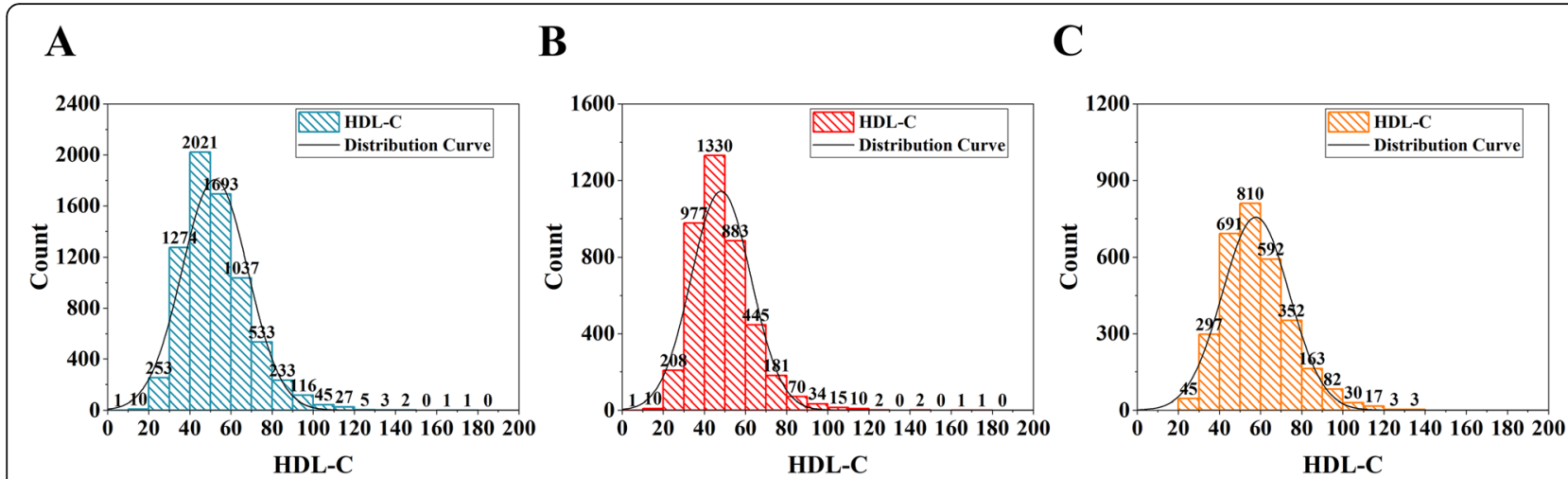

Fig. 2 Distribution histogram of HDL-C. a. Among all participants; b. Among all males; c. Among all females. HDL-C, high-density lipoprotein cholesterol

respectively. The mean HDL-C level among all participants was $52.47 \pm 15.94 \mathrm{mg} / \mathrm{dL}$. In addition, the distribution of HDL-C, including among all participants, all males or all females, is presented in Fig. 2. The detailed results and other baseline characteristics are presented in Table 1 .

\section{Relationship between HDL-C and BMD}

HDL-C levels displayed a negative association with BMD $(P<0.01)$ in Model 1 (no covariates were adjusted). Moreover, after adjusting for confounders (Model 2: age, sex, and race/ethnicity were adjusted; Model 3: age, sex, race/ ethnicity, education level, income to poverty ratio, BMI, alcohol consumption status, smoking status, diabetes, hypertension, ALT, AST, total calcium, cholesterol, and C-reactive protein were adjusted), a negative association was still present and statistically significant. Moreover, a negative association was also observed in the nonlinear relationship between HDL-C levels and BMD assessed by smooth curve fittings and generalized additive models. The detailed results are displayed in Table 2 and Fig. 3.

\section{Subgroup analysis}

After adjusting for covariates, the results of subgroup analysis showed that the association between HDL-C levels and BMD was mainly present in females or participants aged 30 to 39 or 50-59 years. Detailed information on the subgroup analysis is shown in Tables 3-4.

For males, HDL-C levels exhibited an inverse association with BMD in Model 1 and Model 2. However, when all covariates were adjusted, this relationship was not present. In addition, when the nonlinear relationship was characterized by smooth curve fittings and generalized additive models, the inverse correlation between HDL-C levels and BMD did not survive in most groups. The detailed results are listed in Table 5 and Fig. 4.

For females, HDL-C levels displayed a negative association with BMD among all age groups in Model 1 and Model 2. However, when all covariates were adjusted, the results suggested that the negative association was mainly among women aged 30 to 40 or 50 to 60 . Further analysis of the nonlinear relationship between HDL-C and BMD showed that (i) HDL-C levels displayed an inverted Ushaped relationship with BMD among women aged 30 to 39 or over 60 years. Moreover, the inflection points of HDL-C observed were approximately $45 \mathrm{mg} / \mathrm{dL}$ (for subjects aged 30 to 40 or subjects over 60 ). In addition, the two-piecewise linear regression models demonstrated that BMD rose gradually as the HDL-C level rose (HDL-C < $45 \mathrm{mg} / \mathrm{dL}$ ), while no statistical significance was observed in females aged 30 to 39; BMD declined gradually as the HDL-C level rose (HDL-C $>45 \mathrm{mg} / \mathrm{dL}$ ), while no statistical significance was observed in females aged over 60. (ii) HDL-C levels exhibited a U-shaped association with BMD among women aged 20 to 29 or 50 to 59 years. Moreover, the thresholds of the inflection points observed were approximately $65 \mathrm{mg} / \mathrm{dL}$ (subject aged 20 to 29) and $70 \mathrm{mg} /$ $\mathrm{dL}$ (subject aged 50 to 59 ). In addition, the two-piecewise linear regression models demonstrated that BMD declined gradually with the rising HDL-C level (HDL-C less than the threshold); BMD rose gradually with the rising HDL$\mathrm{C}$ level (HDL-C greater than the threshold), while no statistical significance was observed in females aged 50 to 59 . The detailed results are listed in Tables 6-7 and Fig. 5.

\section{Relationship between HDL-C levels and bone loss}

To explore whether HDL-C had potential value in predicting osteopenia or osteoporosis, the female participants were subdivided into three groups (low HDL-C tertile: $21-48 \mathrm{mg} / \mathrm{dL}$; middle HDL-C tertile: $49-61 \mathrm{mg} /$ $\mathrm{dL}$; high HDL-C tertile: $62-139 \mathrm{mg} / \mathrm{dL}$ ). Since the sample size of the osteoporosis or osteopenia participants was much smaller than that of the normal BMD group after weighing, the OR value and $95 \%$ CI could not be calculated; thus, the sample numbers were not weighted in this analysis. After adjusting for confounders, compared with the participants with middle HDL-C levels 
Table 1 Weighted characteristics of the study population

\begin{tabular}{|c|c|}
\hline Characteristics & Means or proportions \\
\hline Age (years, mean $\pm S D$ ) & $41.74 \pm 14.25$ \\
\hline \multicolumn{2}{|l|}{ Sex, n (\%) } \\
\hline Male & $4170(56.93)$ \\
\hline Female & $3085(43.07)$ \\
\hline \multicolumn{2}{|l|}{ Race/ethnicity, n (\%) } \\
\hline Mexican American & $1429(8.85)$ \\
\hline Other Hispanic & $626(4.71)$ \\
\hline Non-Hispanic White & $3397(69.43)$ \\
\hline Non-Hispanic Black & $1445(10.70)$ \\
\hline Other Race & $358(6.30)$ \\
\hline \multicolumn{2}{|l|}{ Education level, n (\%) } \\
\hline Under high school & $1913(17.14)$ \\
\hline High school or equivalent & $1662(23.01)$ \\
\hline Above high school & $3680(59.85)$ \\
\hline Income to poverty ratio (mean $\pm S D$ ) & $3.10 \pm 1.63$ \\
\hline \multicolumn{2}{|l|}{ BMI, n (\%) } \\
\hline$>=30$ & $2008(25.83)$ \\
\hline$>=25,<30$ & $2704(36.50)$ \\
\hline$<25$ & $2543(37.68)$ \\
\hline \multicolumn{2}{|l|}{ Smoked at least 100 cigarettes in life, n (\%) } \\
\hline Yes & $3394(46.31)$ \\
\hline No & $3861(53.69)$ \\
\hline \multicolumn{2}{|c|}{ Had at least 12 alcohol drinks past one year? n (\%) } \\
\hline Yes & $5462(79.20)$ \\
\hline No & $1793(20.80)$ \\
\hline \multicolumn{2}{|l|}{ Hypertension, n (\%) } \\
\hline Yes & $1844(22.18)$ \\
\hline No & $5411(77.82)$ \\
\hline \multicolumn{2}{|l|}{ Diabetes, n (\%) } \\
\hline Yes & $564(5.38)$ \\
\hline No & $6590(93.42)$ \\
\hline Borderline & $101(1.21)$ \\
\hline $\mathrm{ALT}(\mathrm{U} / \mathrm{L}$, mean $\pm \mathrm{SD})$ & $26.48 \pm 18.83$ \\
\hline $\mathrm{AST}(\mathrm{U} / \mathrm{L}$, mean $\pm \mathrm{SD})$ & $25.75 \pm 14.10$ \\
\hline Total calcium (mg/dL, mean \pm SD) & $9.46 \pm 0.35$ \\
\hline Cholesterol (mg/dL, mean \pm SD) & $196.71 \pm 40.39$ \\
\hline C-reactive protein $(\mathrm{mg} / \mathrm{dL}$, mean $\pm \mathrm{SD})$ & $0.33 \pm 0.68$ \\
\hline $\mathrm{HDL}-\mathrm{C}(\mathrm{mg} / \mathrm{dL}$, mean $\pm \mathrm{SD})$ & $52.47 \pm 15.94$ \\
\hline Total femur BMD (g/cm2, mean $\pm \mathrm{SD})$ & $1.00 \pm 0.15$ \\
\hline Femur neck BMD (g/cm2, mean $\pm \mathrm{SD})$ & $0.86 \pm 0.14$ \\
\hline Trochanter BMD (g/cm2, mean \pm SD) & $0.75 \pm 0.13$ \\
\hline Intertrochanter BMD (g/cm2, mean $\pm \mathrm{SD})$ & $1.17 \pm 0.18$ \\
\hline Total spine BMD (g/cm2, mean \pm SD) & $1.05 \pm 0.14$ \\
\hline L1 BMD (g/cm2, mean $\pm \mathrm{SD})$ & $0.97 \pm 0.14$ \\
\hline
\end{tabular}

Table 1 Weighted characteristics of the study population (Continued)

\begin{tabular}{|c|c|}
\hline Characteristics & Means or proportions \\
\hline L2 BMD (g/cm2, mean \pm SD) & $1.06 \pm 0.15$ \\
\hline L3 BMD (g/cm2, mean \pm SD) & $1.08 \pm 0.15$ \\
\hline L4 BMD (g/cm2, mean $\pm \mathrm{SD})$ & $1.08 \pm 0.14$ \\
\hline
\end{tabular}

(49-61 mg/dL), females with high HDL-C levels (62-139 $\mathrm{mg} / \mathrm{dL}$ ) had an increased risk of osteopenia or osteoporosis, especially women aged 40-59. In addition, females aged 40-49 who had low HDL-C levels $(21-48 \mathrm{mg} / \mathrm{dL})$ also had a high incidence of osteopenia or osteoporosis. The specific results are listed in Table 8.

\section{Discussion}

In the present study, HDL-C displayed a negative correlation with BMD, especially in females. Moreover, a nonlinear relationship between HDL-C and BMD was observed among females across different age ranges. Additionally, females with high HDL-C levels had an increased incidence of osteopenia or osteoporosis, which suggests that HDL-C levels might have potential predictive value for osteopenia or osteoporosis.

Previous studies have explored the relationship between HDL-C and BMD [17-20]. For example, in Iranian women, Maghbooli et al. found that HDL-C levels displayed an inversely correlation with BMD in postmenopausal women with vitamin $\mathrm{D}$ deficiency [17]. Zhang et al. demonstrated that HDL-C exhibited a negative association with BMD in Chinese women above 50 years of age [18]. Makovey et al. observed a modest inverse relationship between hip BMD and HDL-C in postmenopausal women [31]. Jeong et al. found that HDL-C levels displayed a positive correlation with BMD in postmenopausal women, but the positive correlation was too weak $(\beta<0.001)$ [20]. Cui et al. demonstrated that HDL-C levels were not linked to BMD in pre- or postmenopausal women [19]. In summary, the conclusions remain controversial, and these studies had limitations, such as a small sample size, a selected population, or adjusted variables; however, the present study avoids these shortcomings. First, this study used a nationally representative sample from the NHANES database, which allowed a huge sample size. Second, since previous studies usually considered the relationship between HDL-C and BMD in females, especially postmenopausal females, the present study also considered the potential impact of gender and age. Third, this study adjusted for more variables that might potentially influence BMD. As expected, here, this study demonstrated not only a correlation between HDL-C and BMD but also a potential 
Table 2 Association between HDL-C and BMD

\begin{tabular}{|c|c|c|c|}
\hline & $\begin{array}{l}\text { Model } 1 \\
\beta(95 \% \mathrm{Cl}) P \text { value }\end{array}$ & $\begin{array}{l}\text { Model } 2 \\
\beta(95 \% \mathrm{Cl}) P \text { value }\end{array}$ & $\begin{array}{l}\text { Model } 3 \\
\beta(95 \% \mathrm{Cl}) P \text { value }\end{array}$ \\
\hline Total femur BMD & $-0.0023(-0.0025,-0.0021)<0.000001$ & $-0.0013(-0.0015,-0.0011)<0.000001$ & $-0.0004(-0.0006,-0.0002) 0.000668$ \\
\hline Femur neck BMD & $-0.0017(-0.0019,-0.0015)<0.000001$ & $-0.0011(-0.0013,-0.0009)<0.000001$ & $-0.0003(-0.0005,-0.0001) 0.004985$ \\
\hline Trochanter BMD & $-0.0016(-0.0018,-0.0014)<0.000001$ & $-0.0008(-0.0010,-0.0007)<0.000001$ & $-0.0002(-0.0004,-0.0001) 0.012022$ \\
\hline Intertrochanter BMD & $-0.0027(-0.0029,-0.0024)<0.000001$ & $-0.0016(-0.0018,-0.0013)<0.000001$ & $-0.0005(-0.0007,-0.0002) 0.000301$ \\
\hline Total spine BMD & $-0.0010(-0.0012,-0.0008)<0.000001$ & $-0.0010(-0.0012,-0.0008)<0.000001$ & $-0.0004(-0.0006,-0.0002) 0.001002$ \\
\hline L1 BMD & $-0.0016(-0.0018,-0.0014)<0.000001$ & $-0.0012(-0.0014,-0.0009)<0.000001$ & $-0.0005(-0.0007,-0.0002) 0.000112$ \\
\hline L2 BMD & $-0.0012(-0.0014,-0.0010)<0.000001$ & $-0.0011(-0.0013,-0.0009)<0.000001$ & $-0.0005(-0.0007,-0.0003) 0.000030$ \\
\hline L3 BMD & $-0.0007(-0.0009,-0.0005)<0.000001$ & $-0.0009(-0.0011,-0.0007)<0.000001$ & $-0.0003(-0.0006,-0.0001) 0.005108$ \\
\hline L4 BMD & $-0.0006(-0.0008,-0.0004)<0.000001$ & $-0.0008(-0.0010,-0.0006)<0.000001$ & $-0.0002(-0.0005,-0.0000) 0.049655$ \\
\hline
\end{tabular}

Model 1: no covariates were adjusted. Model 2: age (20-29, 30-39, 40-49; 50-59; $\geq 60)$, sex (male; female), race/ethnicity (Mexican American; other Hispanic; nonHispanic white; non-Hispanic black; other races) were adjusted. Model 3: age (20-29, 30-39, 40-49; 50-59; $\geq 60$ ), sex (male; female), race/ethnicity (Mexican American; other Hispanic; non-Hispanic white; non-Hispanic black; other races), education level (under high school; high school or equivalent; above high school), income to poverty ratio (quartile groups), BMI (obese, overweight, normal), smoking status (less than 100 cigarettes; greater than or equal to 100 cigarettes), alcohol consumption status (had at least 12 alcohol drinks past one year; have less than 12 alcohol drinks past one year), hypertension (yes; no), diabetes (yes; no; borderline), ALT (quartile groups), AST (quartile groups), total calcium (quartile groups), cholesterol (quartile groups), and C-reactive protein (quartile groups) were adjusted. HDL-C high-density lipoprotein cholesterol; BMD bone mineral density; ALT alanine aminotransferase; AST aspartate aminotransferase

predictive value of HDL-C for osteoporosis or osteopenia.

The mechanisms underlying the correlation between HDL-C and BMD are uncertain. Especially in basic research, there is no robust evidence that supports this negative association. According to related studies, several possible factors might account for this phenomenon. First, HDL-C, especially at a high level, affects BMD through sex hormones. There are already a large number of studies demonstrating that sex hormones, including androgen and oestrogen, play essential roles in maintaining bone balance [32-34]. Semmens et al. found that testosterone levels present a strong negative association with HDL-C levels [35]. Jirapinyo et al. observed that combined oral oestrogen/progestogen increased BMD in postmenopausal women but decreased HDL-C levels [36]. In the present study, a difference in the association between HDL-C and BMD was observed among different gender and age groups, which suggests that hormone levels, especially sex hormones, contribute to the association. However, because the NHANES database 2005-2010 did not collect information on the levels of sex hormones, the sex hormone levels could not be described in the present study. Second, high HDL-C levels might affect BMD by activating an inflammatory reaction. There is already evidence suggesting that inflammatory factors can affect bone metabolism, such as influencing the activation or function of osteoclasts [37, 38], which might be a possible pathway by which high HDL-C levels affect BMD. For example, Mazidi et al. found that HDL-C was positively associated with inflammatory indicators, such as C-reactive protein, white blood cells, and fibrinogen, in adults [39]. However, there is no direct evidence supporting this hypothesis; thus, further experiments are necessary.
The present study not only demonstrates a negative association between HDL-C and BMD but also has certain clinical value that can guide clinicians. Specifically, the negative association suggests that subjects with a higher HDL-C level might have a lower BMD. This study found that females with high HDL-C levels had an increased incidence of osteopenia or osteoporosis. However, it is important to note that although the associations were different according to ages, there may be no clinical implications in some age groups. The results of multiple logistic regression models shows that the females aged 20 to 39 or over 60 with high HDL-C levels did not have a high prevalence of osteoporosis or osteopenia $(\mathrm{P}>0.05)$. Therefore, these findings suggest that clinicians should be alert to the risk of reduced bone mass for individuals with high HDL-C levels, especially postmenopausal women. For these patients, close monitoring of BMD and early intervention may be necessary. In addition, osteoporotic fracture is one of the most common and serious complications for patients with osteoporosis [8]. Therefore, future research is warranted to explore whether high HDL-C levels can indicate an increased risk of osteoporotic fracture.

For a long time, numerous researchers and studies have believed that HDL-C is beneficial to health [40, 41]. Especially in the field of cardiovascular disease [2, 4], HDL-C is considered to be negatively correlated with adverse cardiovascular events [2-5]. However, numerous research results have indicated that the contribution of HDL-C to human health might be highly overestimated. Several years ago, it was demonstrated that drugs that increased HDL-C did not prevent adverse cardiovascular events [42]. Other recent studies have reported that HDL-C displays an inverted U-shaped relationship with 


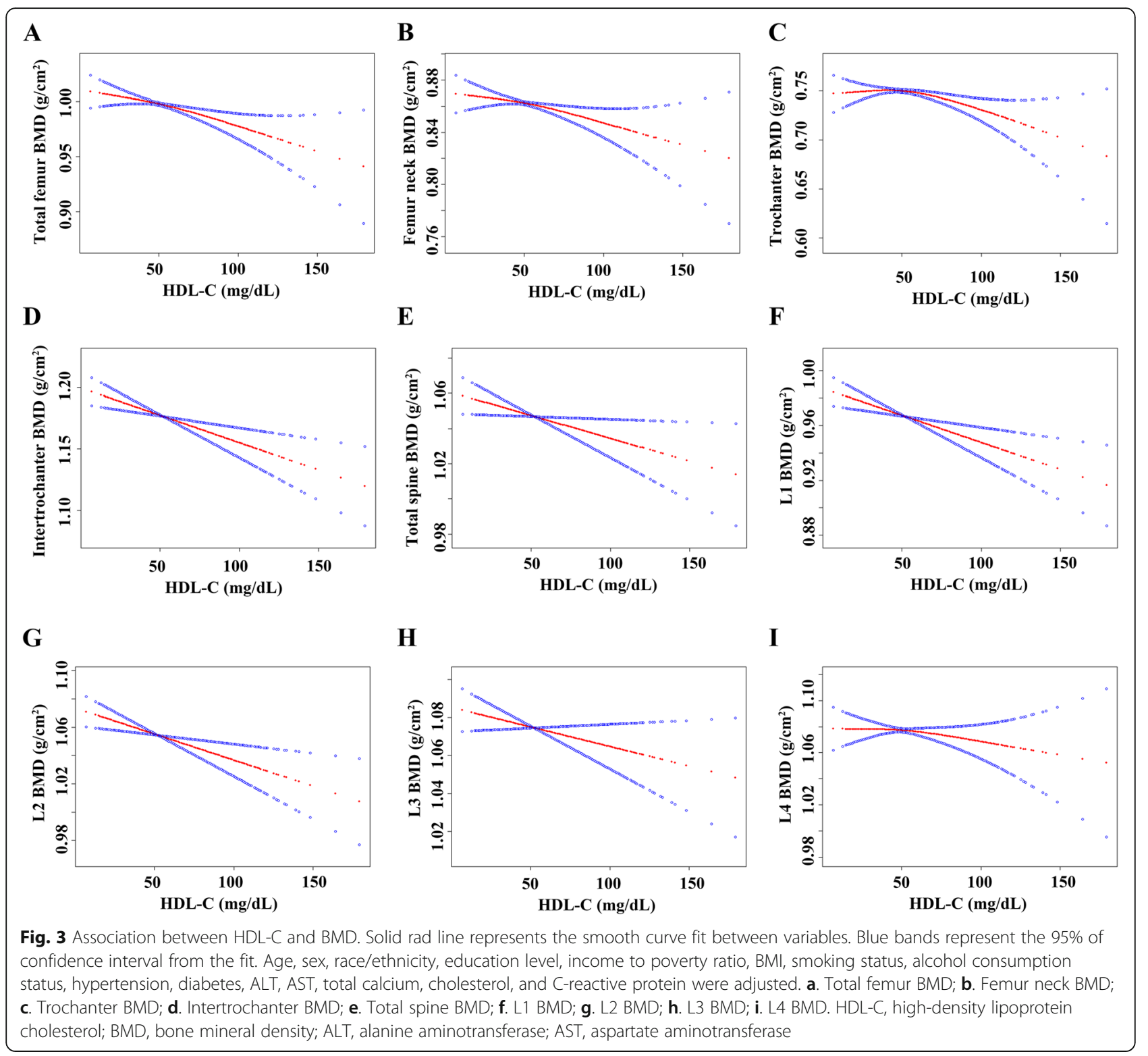

all-cause mortality [7, 43]. All of these findings indicate that elevated HDL-C levels may be detrimental to health and may even cause certain adverse events. This study established that HDL-C exhibits an inverse relationship with BMD in adult females, corroborating this view. In addition, it is worth mentioning that most basic studies usually focus on the impact of low HDL-C but not high HDL-C on bone metabolism [44, 45]. Although many studies have demonstrated that low HDL-C levels can affect bone metabolism through a variety of pathways, there is no evidence to elucidate the impact of high HDL-C levels on bone metabolism, especially the function and activity of osteoblasts and osteoclasts. As a result, future research should focus on the specific mechanism underlying the effect of elevated HDL-C levels on bone metabolism, which is necessary for improving theoretical knowledge of the impact of lipid metabolism on bone balance.

\section{Strength and study limitation}

This study has several strengths for studying the association between HDL-C and BMD. (i) This study was based on data in the NHANES database, which has a large sample size and adequate clinical information. (ii) This study estimated the difference in the association between HDL-C and BMD in diverse populations by stratifying age and sex. (iii) In addition to the linear relationship between HDL-C and BMD, this study also 
Table 3 Association between HDL-C and BMD stratified by age

\begin{tabular}{|c|c|c|c|c|}
\hline & & $\begin{array}{l}\text { Model } 1 \\
\beta(95 \% \mathrm{Cl}) P \text { value }\end{array}$ & $\begin{array}{l}\text { Model } 2 \\
\beta(95 \% \mathrm{Cl}) P \text { value }\end{array}$ & $\begin{array}{l}\text { Model } 3 \\
\beta(95 \% \mathrm{Cl}) P \text { value }\end{array}$ \\
\hline \multirow[t]{5}{*}{ Total femur BMD } & $20 \leq$ Aged $<30$ & $-0.0018(-0.0023,-0.0013)<0.000001$ & $-0.0008(-0.0013,-0.0004) 0.000480$ & $0.0001(-0.0004,0.0006) 0.598614$ \\
\hline & $30 \leq$ Aged $<40$ & $-0.0023(-0.0027,-0.0018)<0.000001$ & $-0.0016(-0.0020,-0.0012)<0.000001$ & $-0.0009(-0.0013,-0.0004) 0.000185$ \\
\hline & $40 \leq$ Aged $<50$ & $-0.0019(-0.0023,-0.0016)<0.000001$ & $-0.0012(-0.0015,-0.0008)<0.000001$ & $-0.0002(-0.0006,0.0002) 0.281833$ \\
\hline & $50 \leq$ Aged $<60$ & $-0.0027(-0.0032,-0.0021)<0.000001$ & $-0.0018(-0.0023,-0.0013)<0.000001$ & $-0.0009(-0.0014,-0.0003) 0.002075$ \\
\hline & $60 \leq$ Aged & $-0.0029(-0.0035,-0.0023)<0.000001$ & $-0.0012(-0.0017,-0.0007) 0.000012$ & $-0.0003(-0.0008,0.0003) 0.327776$ \\
\hline \multirow[t]{5}{*}{ Femur neck BMD } & $20 \leq$ Aged $<30$ & $-0.0014(-0.0018,-0.0009)<0.000001$ & $-0.0007(-0.0012,-0.0003) 0.001761$ & $0.0002(-0.0003,0.0007) 0.335319$ \\
\hline & $30 \leq$ Aged $<40$ & $-0.0015(-0.0019,-0.0011)<0.000001$ & $-0.0013(-0.0017,-0.0009)<0.000001$ & $-0.0006(-0.0011,-0.0002) 0.008064$ \\
\hline & $40 \leq$ Aged $<50$ & $-0.0013(-0.0017,-0.0010)<0.000001$ & $-0.0011(-0.0014,-0.0007)<0.000001$ & $-0.0003(-0.0007,0.0001) 0.149013$ \\
\hline & $50 \leq$ Aged $<60$ & $-0.0019(-0.0023,-0.0015)<0.000001$ & $-0.0015(-0.0020,-0.0011)<0.000001$ & $-0.0007(-0.0012,-0.0001) 0.011229$ \\
\hline & $60 \leq$ Aged & $-0.0020(-0.0025,-0.0015)<0.000001$ & $-0.0011(-0.0016,-0.0006) 0.000009$ & $-0.0003(-0.0008,0.0002) 0.195810$ \\
\hline \multirow[t]{5}{*}{ Trochanter BMD } & $20 \leq$ Aged $<30$ & $-0.0013(-0.0018,-0.0009)<0.000001$ & $-0.0005(-0.0009,-0.0001) 0.008268$ & $-0.0000(-0.0005,0.0004) 0.936942$ \\
\hline & $30 \leq$ Aged $<40$ & $-0.0015(-0.0019,-0.0012)<0.000001$ & $-0.0010(-0.0014,-0.0006)<0.000001$ & $-0.0006(-0.0010,-0.0002) 0.007441$ \\
\hline & $40 \leq$ Aged $<50$ & $-0.0013(-0.0017,-0.0010)<0.000001$ & $-0.0007(-0.0011,-0.0004) 0.000022$ & $-0.0002(-0.0005,0.0002) 0.342789$ \\
\hline & $50 \leq$ Aged $<60$ & $-0.0020(-0.0025,-0.0016)<0.000001$ & $-0.0013(-0.0018,-0.0008)<0.000001$ & $-0.0007(-0.0012,-0.0001) 0.013165$ \\
\hline & $60 \leq$ Aged & $-0.0021(-0.0026,-0.0016)<0.000001$ & $-0.0006(-0.0010,-0.0001) 0.011620$ & $0.0000(-0.0004,0.0005) 0.930179$ \\
\hline \multirow[t]{5}{*}{ Intertrochanter BMD } & $20 \leq$ Aged $<30$ & $-0.0021(-0.0027,-0.0016)<0.000001$ & $-0.0010(-0.0015,-0.0005) 0.000211$ & $0.0001(-0.0005,0.0007) 0.697817$ \\
\hline & $30 \leq$ Aged $<40$ & $-0.0027(-0.0032,-0.0022)<0.000001$ & $-0.0019(-0.0024,-0.0014)<0.000001$ & $-0.0011(-0.0016,-0.0006) 0.000067$ \\
\hline & $40 \leq$ Aged $<50$ & $-0.0023(-0.0028,-0.0019)<0.000001$ & $-0.0014(-0.0018,-0.0009)<0.000001$ & $-0.0002(-0.0007,0.0003) 0.365447$ \\
\hline & $50 \leq$ Aged $<60$ & $-0.0031(-0.0037,-0.0025)<0.000001$ & $-0.0021(-0.0028,-0.0015)<0.000001$ & $-0.0010(-0.0017,-0.0004) 0.002512$ \\
\hline & $60 \leq$ Aged & $-0.0035(-0.0042,-0.0029)<0.000001$ & $-0.0016(-0.0022,-0.0009) 0.000002$ & $-0.0005(-0.0011,0.0002) 0.160472$ \\
\hline \multirow[t]{5}{*}{ Total spine BMD } & $20 \leq$ Aged $<30$ & $-0.0005(-0.0009,-0.0002) 0.006856$ & $-0.0007(-0.0011,-0.0003) 0.000465$ & $-0.0001(-0.0006,0.0003) 0.540391$ \\
\hline & $30 \leq$ Aged $<40$ & $-0.0005(-0.0009,-0.0001) 0.021297$ & $-0.0009(-0.0013,-0.0005) 0.000009$ & $-0.0006(-0.0010,-0.0001) 0.012320$ \\
\hline & $40 \leq$ Aged $<50$ & $-0.0004(-0.0007,-0.0000) 0.037080$ & $-0.0007(-0.0011,-0.0003) 0.000666$ & $-0.0001(-0.0005,0.0004) 0.795368$ \\
\hline & $50 \leq$ Aged $<60$ & $-0.0021(-0.0026,-0.0016)<0.000001$ & $-0.0019(-0.0024,-0.0013)<0.000001$ & $-0.0012(-0.0018,-0.0005) 0.000354$ \\
\hline & $60 \leq$ Aged & $-0.0024(-0.0030,-0.0018)<0.000001$ & $-0.0010(-0.0016,-0.0004) 0.000661$ & $-0.0004(-0.0010,0.0002) 0.171588$ \\
\hline \multirow[t]{5}{*}{ L1 BMD } & $20 \leq$ Aged $<30$ & $-0.0009(-0.0013,-0.0004) 0.000068$ & $-0.0006(-0.0011,-0.0002) 0.003937$ & $0.0001(-0.0004,0.0006) 0.734575$ \\
\hline & $30 \leq$ Aged $<40$ & $-0.0011(-0.0015,-0.0007)<0.000001$ & $-0.0010(-0.0015,-0.0006) 0.000003$ & $-0.0006(-0.0011,-0.0001) 0.015966$ \\
\hline & $40 \leq$ Aged $<50$ & $-0.0011(-0.0015,-0.0008)<0.000001$ & $-0.0009(-0.0013,-0.0005) 0.000013$ & $-0.0002(-0.0007,0.0002) 0.357967$ \\
\hline & $50 \leq$ Aged $<60$ & $-0.0028(-0.0033,-0.0022)<0.000001$ & $-0.0022(-0.0027,-0.0016)<0.000001$ & $-0.0014(-0.0020,-0.0008) 0.000018$ \\
\hline & $60 \leq$ Aged & $-0.0033(-0.0039,-0.0026)<0.000001$ & $-0.0014(-0.0020,-0.0009)<0.000001$ & $-0.0007(-0.0013,-0.0001) 0.020440$ \\
\hline \multirow[t]{5}{*}{ L2 BMD } & $20 \leq$ Aged $<30$ & $-0.0007(-0.0011,-0.0003) 0.001453$ & $-0.0008(-0.0012,-0.0003) 0.000564$ & $-0.0001(-0.0006,0.0003) 0.585766$ \\
\hline & $30 \leq$ Aged $<40$ & $-0.0007(-0.0011,-0.0003) 0.001105$ & $-0.0011(-0.0015,-0.0006) 0.000003$ & $-0.0007(-0.0012,-0.0002) 0.005244$ \\
\hline & $40 \leq$ Aged $<50$ & $-0.0006(-0.0010,-0.0002) 0.001416$ & $-0.0008(-0.0012,-0.0004) 0.000099$ & $-0.0002(-0.0007,0.0002) 0.353490$ \\
\hline & $50 \leq$ Aged $<60$ & $-0.0023(-0.0029,-0.0017)<0.000001$ & $-0.0020(-0.0026,-0.0014)<0.000001$ & $-0.0014(-0.0021,-0.0007) 0.000065$ \\
\hline & $60 \leq$ Aged & $-0.0027(-0.0033,-0.0021)<0.000001$ & $-0.0011(-0.0017,-0.0005) 0.000327$ & $-0.0006(-0.0012,0.0001) 0.079934$ \\
\hline \multirow[t]{5}{*}{ L3 BMD } & $20 \leq$ Aged $<30$ & $-0.0003(-0.0008,0.0001) 0.106832$ & $-0.0007(-0.0012,-0.0003) 0.000815$ & $-0.0002(-0.0007,0.0002) 0.312215$ \\
\hline & $30 \leq$ Aged $<40$ & $-0.0001(-0.0005,0.0003) 0.650876$ & $-0.0009(-0.0013,-0.0004) 0.000094$ & $-0.0006(-0.0011,-0.0001) 0.012140$ \\
\hline & $40 \leq$ Aged $<50$ & $0.0001(-0.0003,0.0005) 0.712982$ & $-0.0005(-0.0009,-0.0001) 0.027419$ & $0.0001(-0.0004,0.0005) 0.761201$ \\
\hline & $50 \leq$ Aged $<60$ & $-0.0019(-0.0025,-0.0013)<0.000001$ & $-0.0019(-0.0025,-0.0013)<0.000001$ & $-0.0013(-0.0020,-0.0006) 0.000341$ \\
\hline & $60 \leq$ Aged & $-0.0022(-0.0028,-0.0015)<0.000001$ & $-0.0009(-0.0015,-0.0002) 0.007370$ & $-0.0002(-0.0009,0.0005) 0.588529$ \\
\hline \multirow[t]{3}{*}{ L4 BMD } & $20 \leq$ Aged $<30$ & $-0.0004(-0.0008,0.0000) 0.060890$ & $-0.0008(-0.0012,-0.0003) 0.000663$ & $-0.0002(-0.0007,0.0003) 0.373641$ \\
\hline & $30 \leq$ Aged $<40$ & $-0.0001(-0.0005,0.0003) 0.679656$ & $-0.0008(-0.0012,-0.0003) 0.000554$ & $-0.0004(-0.0009,0.0001) 0.086672$ \\
\hline & $40 \leq$ Aged $<50$ & $-0.0001(-0.0005,0.0003) 0.712879$ & $-0.0006(-0.0010,-0.0002) 0.006600$ & $0.0001(-0.0004,0.0005) 0.810854$ \\
\hline
\end{tabular}


Table 3 Association between HDL-C and BMD stratified by age (Continued)

\begin{tabular}{llll}
\hline & Model 1 & Model 2 & \multicolumn{1}{c}{ Model $\mathbf{3}$} \\
& $\boldsymbol{\beta}(\mathbf{9 5 \%} \mathrm{Cl}) \boldsymbol{P}$ value & $\boldsymbol{\beta}(\mathbf{9 5 \%} \mathrm{Cl}) \boldsymbol{P}$ value & $\boldsymbol{\beta}(\mathbf{9 5 \%} \mathrm{Cl}) \boldsymbol{P}$ value \\
\hline $50 \leq$ Aged $<60$ & $-0.0017(-0.0022,-0.0011)<0.000001$ & $-0.0016(-0.0022,-0.0010)<0.000001$ & $-0.0008(-0.0014,-0.0001) 0.029822$ \\
$60 \leq$ Aged & $-0.0019(-0.0026,-0.0013)<0.000001$ & $-0.0007(-0.0014,-0.0001) 0.022931$ & $-0.0003(-0.0010,0.0004) 0.399114$ \\
\hline
\end{tabular}

Model 1: no covariates were adjusted. Model 2: sex (male; female) and race/ethnicity (Mexican American; other Hispanic; non-Hispanic white; non-Hispanic black; other Races) were adjusted. Model 3: sex (male; female), race/ethnicity (Mexican American; other Hispanic; non-Hispanic white; non-Hispanic black; other races), education level (under high school; high school or equivalent; above high school), income to poverty ratio (quartile groups), BMI (obese, overweight, normal), smoking status (less than 100 cigarettes; greater than or equal to 100 cigarettes), alcohol consumption status (had at least 12 alcohol drinks past one year; have less than 12 alcohol drinks past one year), hypertension (yes; no), diabetes (yes; no; borderline), ALT (quartile groups), AST (quartile groups), total calcium (quartile groups), cholesterol (quartile groups), and C-reactive protein (quartile groups) were adjusted. HDL-C high-density lipoprotein cholesterol; BMD bone mineral density; ALT alanine aminotransferase; AST aspartate aminotransferase

employed statistical analyses assessing a nonlinear model. (iv) This study found that female participants with higher HDL-C levels had an increased incidence of osteopenia or osteoporosis, which suggests that HDL-C might have potential value for predicting osteopenia or osteoporosis. In addition, this study has some limitations: (i) This study is based on American participants. Because of the differences in genetic, lingual, cultural, and environmental factors, it is uncertain whether the association between HDL-C and BMD applies to other countries or races. (ii) Because some related information, such as sex hormone and parathyroid hormone levels, was not provided in the NHANES database 2005-2010, this study could not describe these conditions in current cases. (iii) The questionnaire data were collected through questionnaires and interviews, which may lead to recall bias and potentially affect the research conclusion. (iv) Because of the cross-sectional study design, the causal involvement of HDL-C and BMD could not be confirmed. Moreover, there may be some potential confounding factors that were not adjusted.

Table 4 Association between HDL-C and BMD stratified by sex

\begin{tabular}{|c|c|c|c|c|}
\hline & & $\begin{array}{l}\text { Model } 1 \\
\beta(95 \% \mathrm{Cl}) P \text { value }\end{array}$ & $\begin{array}{l}\text { Model } 2 \\
\beta(95 \% \mathrm{Cl}) P \text { value }\end{array}$ & $\begin{array}{l}\text { Model } 3 \\
\beta(95 \% \mathrm{Cl}) P \text { value }\end{array}$ \\
\hline \multirow[t]{2}{*}{ Total femur BMD } & Male & $-0.0011(-0.0014,-0.0008)<0.000001$ & $-0.0012(-0.0015,-0.0009)<0.000001$ & $-0.0002(-0.0006,0.0001) 0.116880$ \\
\hline & Female & $-0.0015(-0.0018,-0.0012)<0.000001$ & $-0.0014(-0.0017,-0.0012)<0.000001$ & $-0.0005(-0.0008,-0.0002) 0.000302$ \\
\hline \multirow[t]{2}{*}{ Femur neck BMD } & Male & $-0.0009(-0.0012,-0.0006)<0.000001$ & $-0.0010(-0.0012,-0.0007)<0.000001$ & $-0.0001(-0.0004,0.0002) 0.449640$ \\
\hline & Female & $-0.0015(-0.0018,-0.0012)<0.000001$ & $-0.0013(-0.0016,-0.0011)<0.000001$ & $-0.0005(-0.0008,-0.0002) 0.000374$ \\
\hline \multirow[t]{2}{*}{ Trochanter BMD } & Male & $-0.0006(-0.0008,-0.0003) 0.000047$ & $-0.0007(-0.0010,-0.0004)<0.000001$ & $-0.0001(-0.0004,0.0002) 0.422344$ \\
\hline & Female & $-0.0010(-0.0013,-0.0008)<0.000001$ & $-0.0010(-0.0012,-0.0008)<0.000001$ & $-0.0004(-0.0007,-0.0002) 0.001635$ \\
\hline \multirow[t]{2}{*}{ Intertrochanter BMD } & Male & $-0.0013(-0.0017,-0.0010)<0.000001$ & $-0.0015(-0.0018,-0.0011)<0.000001$ & $-0.0003(-0.0007,0.0000) 0.063777$ \\
\hline & Female & $-0.0018(-0.0021,-0.0015)<0.000001$ & $-0.0017(-0.0020,-0.0014)<0.000001$ & $-0.0006(-0.0010,-0.0003) 0.000359$ \\
\hline \multirow[t]{2}{*}{ Total spine BMD } & Male & $-0.0005(-0.0008,-0.0002) 0.002365$ & $-0.0007(-0.0010,-0.0004) 0.000003$ & $-0.0001(-0.0004,0.0002) 0.520811$ \\
\hline & Female & $-0.0013(-0.0016,-0.0010)<0.000001$ & $-0.0013(-0.0015,-0.0010)<0.000001$ & $-0.0007(-0.0010,-0.0004) 0.000009$ \\
\hline \multirow[t]{2}{*}{ L1 BMD } & Male & $-0.0006(-0.0009,-0.0003) 0.000064$ & $-0.0008(-0.0011,-0.0005)<0.000001$ & $-0.0001(-0.0004,0.0003) 0.676951$ \\
\hline & Female & $-0.0016(-0.0019,-0.0012)<0.000001$ & $-0.0015(-0.0018,-0.0012)<0.000001$ & $-0.0008(-0.0012,-0.0005)<0.000001$ \\
\hline \multirow[t]{2}{*}{ L2 BMD } & Male & $-0.0006(-0.0009,-0.0003) 0.000265$ & $-0.0008(-0.0011,-0.0005)<0.000001$ & $-0.0003(-0.0006,0.0001) 0.135526$ \\
\hline & Female & $-0.0014(-0.0017,-0.0011)<0.000001$ & $-0.0014(-0.0017,-0.0011)<0.000001$ & $-0.0008(-0.0011,-0.0005) 0.000003$ \\
\hline \multirow[t]{2}{*}{ L3 BMD } & Male & $-0.0004(-0.0007,-0.0000) 0.027488$ & $-0.0006(-0.0009,-0.0003) 0.000127$ & $-0.0001(-0.0004,0.0002) 0.584406$ \\
\hline & Female & $-0.0012(-0.0015,-0.0009)<0.000001$ & $-0.0012(-0.0015,-0.0009)<0.000001$ & $-0.0007(-0.0010,-0.0003) 0.000073$ \\
\hline \multirow[t]{2}{*}{ L4 BMD } & Male & $-0.0003(-0.0006,0.0000) 0.059045$ & $-0.0006(-0.0009,-0.0003) 0.000131$ & $0.0000(-0.0003,0.0004) 0.962035$ \\
\hline & Female & $-0.0011(-0.0014,-0.0007)<0.000001$ & $-0.0011(-0.0014,-0.0008)<0.000001$ & $-0.0006(-0.0009,-0.0002) 0.000690$ \\
\hline
\end{tabular}

Model 1: no covariates were adjusted. Model 2: age (20-29, 30-39, 40-49; 50-59; $\geq 60$ ) and race/ethnicity (Mexican American; other Hispanic; non-Hispanic white; non-Hispanic black; other races) were adjusted. Model 3: age (20-29, 30-39, 40-49; 50-59; $\geq 60)$, race/ethnicity (Mexican American; other Hispanic; non-Hispanic white; non-Hispanic black; other races), education level (under high school; high school or equivalent; above high school), income to poverty ratio (quartile groups), BMI (obese, overweight, normal), smoking status (less than 100 cigarettes; greater than or equal to 100 cigarettes), alcohol consumption status (had at least 12 alcohol drinks past one year; have less than 12 alcohol drinks past one year), hypertension (yes; no), diabetes (yes; no; borderline), ALT (quartile groups), AST (quartile groups), total calcium (quartile groups), cholesterol (quartile groups), and C-reactive protein (quartile groups) were adjusted. HDL-C high-density lipoprotein cholesterol; BMD bone mineral density; $A L T$ alanine aminotransferase; $A S T$ aspartate aminotransferase 
Table 5 Association between HDL-C and BMD in males

\begin{tabular}{|c|c|c|c|c|}
\hline & & $\begin{array}{l}\text { Model } 1 \\
\beta(95 \% \mathrm{Cl}) P \text { value }\end{array}$ & $\begin{array}{l}\text { Model } 2 \\
\beta(95 \% \mathrm{Cl}) P \text { value }\end{array}$ & $\begin{array}{l}\text { Model } 3 \\
\beta(95 \% \mathrm{Cl}) P \text { value }\end{array}$ \\
\hline \multirow[t]{5}{*}{ Total femur BMD } & $20 \leq$ Aged $<30$ & $-0.0006(-0.0013,0.0001) 0.118476$ & $-0.0009(-0.0016,-0.0001) 0.017990$ & $0.0001(-0.0007,0.0009) 0.776354$ \\
\hline & $30 \leq$ Aged $<40$ & $-0.0014(-0.0021,-0.0008) 0.000015$ & $-0.0015(-0.0022,-0.0009) 0.000003$ & $-0.0008(-0.0015,-0.0001) 0.019154$ \\
\hline & $40 \leq$ Aged $<50$ & $-0.0007(-0.0012,-0.0001) 0.028729$ & $-0.0009(-0.0015,-0.0003) 0.003117$ & $0.0001(-0.0006,0.0007) 0.820437$ \\
\hline & $50 \leq$ Aged $<60$ & $-0.0013(-0.0021,-0.0006) 0.000698$ & $-0.0017(-0.0024,-0.0009) 0.000026$ & $-0.0005(-0.0014,0.0003) 0.203276$ \\
\hline & $60 \leq$ Aged & $-0.0011(-0.0018,-0.0004) 0.002495$ & $-0.0012(-0.0019,-0.0005) 0.000605$ & $-0.0004(-0.0011,0.0003) 0.220103$ \\
\hline \multirow[t]{5}{*}{ Femur neck BMD } & $20 \leq$ Aged $<30$ & $-0.0005(-0.0012,0.0002) 0.165831$ & $-0.0008(-0.0015,-0.0001) 0.032699$ & $0.0002(-0.0006,0.0010) 0.639104$ \\
\hline & $30 \leq$ Aged $<40$ & $-0.0010(-0.0017,-0.0004) 0.002135$ & $-0.0011(-0.0017,-0.0005) 0.000712$ & $-0.0004(-0.0011,0.0002) 0.198245$ \\
\hline & $40 \leq$ Aged $<50$ & $-0.0006(-0.0012,-0.0001) 0.032023$ & $-0.0009(-0.0014,-0.0003) 0.001909$ & $-0.0001(-0.0007,0.0005) 0.673213$ \\
\hline & $50 \leq$ Aged $<60$ & $-0.0008(-0.0014,-0.0001) 0.021113$ & $-0.0011(-0.0017,-0.0004) 0.001188$ & $0.0000(-0.0007,0.0007) 0.906714$ \\
\hline & $60 \leq$ Aged & $-0.0009(-0.0015,-0.0002) 0.007393$ & $-0.0011(-0.0017,-0.0004) 0.001304$ & $-0.0004(-0.0010,0.0003) 0.281805$ \\
\hline \multirow[t]{5}{*}{ Trochanter BMD } & $20 \leq$ Aged $<30$ & $-0.0003(-0.0009,0.0003) 0.348101$ & $-0.0005(-0.0011,0.0001) 0.113008$ & $-0.0001(-0.0008,0.0006) 0.827111$ \\
\hline & $30 \leq$ Aged $<40$ & $-0.0008(-0.0014,-0.0003) 0.004504$ & $-0.0009(-0.0014,-0.0003) 0.001459$ & $-0.0004(-0.0010,0.0002) 0.155924$ \\
\hline & $40 \leq$ Aged $<50$ & $-0.0003(-0.0008,0.0002) 0.278418$ & $-0.0004(-0.0010,0.0001) 0.101470$ & $0.0001(-0.0005,0.0007) 0.672573$ \\
\hline & $50 \leq$ Aged $<60$ & $-0.0009(-0.0016,-0.0002) 0.009191$ & $-0.0012(-0.0019,-0.0005) 0.000699$ & $-0.0004(-0.0011,0.0004) 0.364990$ \\
\hline & $60 \leq$ Aged & $-0.0004(-0.0010,0.0002) 0.201940$ & $-0.0005(-0.0011,0.0001) 0.106856$ & $-0.0001(-0.0007,0.0005) 0.713744$ \\
\hline \multirow[t]{5}{*}{ Intertrochanter BMD } & $20 \leq$ Aged $<30$ & $-0.0007(-0.0016,0.0001) 0.094572$ & $-0.0011(-0.0019,-0.0002) 0.011121$ & $0.0001(-0.0008,0.0010) 0.769779$ \\
\hline & $30 \leq$ Aged $<40$ & $-0.0018(-0.0026,-0.0011) 0.000003$ & $-0.0019(-0.0027,-0.0012)<0.000001$ & $-0.0011(-0.0019,-0.0003) 0.005767$ \\
\hline & $40 \leq$ Aged $<50$ & $-0.0008(-0.0015,-0.0001) 0.022436$ & $-0.0011(-0.0018,-0.0004) 0.002459$ & $0.0001(-0.0006,0.0009) 0.769447$ \\
\hline & $50 \leq$ Aged $<60$ & $-0.0016(-0.0025,-0.0007) 0.000748$ & $-0.0019(-0.0028,-0.0010) 0.000042$ & $-0.0007(-0.0016,0.0003) 0.190718$ \\
\hline & $60 \leq$ Aged & $-0.0015(-0.0023,-0.0007) 0.000390$ & $-0.0017(-0.0025,-0.0008) 0.000101$ & $-0.0007(-0.0015,0.0001) 0.102944$ \\
\hline \multirow[t]{5}{*}{ Total spine BMD } & $20 \leq$ Aged $<30$ & $-0.0002(-0.0009,0.0004) 0.432167$ & $-0.0005(-0.0011,0.0002) 0.141290$ & $0.0000(-0.0007,0.0007) 0.984658$ \\
\hline & $30 \leq$ Aged $<40$ & $-0.0006(-0.0012,-0.0000) 0.045489$ & $-0.0007(-0.0013,-0.0001) 0.021858$ & $-0.0002(-0.0009,0.0005) 0.545599$ \\
\hline & $40 \leq$ Aged $<50$ & $0.0000(-0.0006,0.0006) 0.894495$ & $-0.0002(-0.0008,0.0004) 0.520570$ & $0.0006(-0.0001,0.0012) 0.086857$ \\
\hline & $50 \leq$ Aged $<60$ & $-0.0013(-0.0021,-0.0005) 0.001560$ & $-0.0017(-0.0025,-0.0009) 0.000021$ & $-0.0007(-0.0016,0.0002) 0.109719$ \\
\hline & $60 \leq$ Aged & $-0.0006(-0.0013,0.0002) 0.140196$ & $-0.0007(-0.0015,0.0000) 0.051753$ & $-0.0006(-0.0014,0.0002) 0.150883$ \\
\hline \multirow[t]{5}{*}{ L1 BMD } & $20 \leq$ Aged $<30$ & $-0.0002(-0.0008,0.0005) 0.627418$ & $-0.0003(-0.0010,0.0003) 0.298880$ & $0.0003(-0.0004,0.0010) 0.458371$ \\
\hline & $30 \leq$ Aged $<40$ & $-0.0005(-0.0012,0.0001) 0.086657$ & $-0.0006(-0.0012,0.0000) 0.053243$ & $-0.0001(-0.0007,0.0006) 0.858850$ \\
\hline & $40 \leq$ Aged $<50$ & $-0.0001(-0.0008,0.0005) 0.668590$ & $-0.0003(-0.0010,0.0003) 0.274953$ & $0.0005(-0.0002,0.0012) 0.125866$ \\
\hline & $50 \leq$ Aged $<60$ & $-0.0015(-0.0023,-0.0007) 0.000174$ & $-0.0019(-0.0027,-0.0011) 0.000002$ & $-0.0008(-0.0016,0.0001) 0.075641$ \\
\hline & $60 \leq$ Aged & $-0.0011(-0.0018,-0.0004) 0.002960$ & $-0.0012(-0.0019,-0.0005) 0.001050$ & $-0.0008(-0.0016,-0.0000) 0.037263$ \\
\hline \multirow[t]{5}{*}{ L2 BMD } & $20 \leq$ Aged $<30$ & $-0.0003(-0.0010,0.0003) 0.348527$ & $-0.0005(-0.0012,0.0001) 0.117012$ & $-0.0001(-0.0008,0.0007) 0.828919$ \\
\hline & $30 \leq$ Aged $<40$ & $-0.0007(-0.0013,-0.0000) 0.046582$ & $-0.0007(-0.0014,-0.0001) 0.023423$ & $-0.0002(-0.0009,0.0005) 0.535701$ \\
\hline & $40 \leq$ Aged $<50$ & $-0.0001(-0.0007,0.0005) 0.815957$ & $-0.0003(-0.0009,0.0003) 0.338671$ & $0.0004(-0.0003,0.0011) 0.221228$ \\
\hline & $50 \leq$ Aged $<60$ & $-0.0015(-0.0023,-0.0007) 0.000477$ & $-0.0019(-0.0027,-0.0011) 0.000008$ & $-0.0011(-0.0020,-0.0001) 0.024255$ \\
\hline & $60 \leq$ Aged & $-0.0005(-0.0013,0.0002) 0.180331$ & $-0.0007(-0.0015,0.0001) 0.075794$ & $-0.0006(-0.0014,0.0002) 0.156083$ \\
\hline \multirow[t]{5}{*}{ L3 BMD } & $20 \leq$ Aged $<30$ & $-0.0002(-0.0009,0.0004) 0.483580$ & $-0.0005(-0.0011,0.0002) 0.173354$ & $-0.0001(-0.0009,0.0006) 0.722289$ \\
\hline & $30 \leq$ Aged $<40$ & $-0.0006(-0.0013,0.0000) 0.061670$ & $-0.0007(-0.0014,-0.0001) 0.029734$ & $-0.0003(-0.0011,0.0004) 0.346774$ \\
\hline & $40 \leq$ Aged $<50$ & $0.0002(-0.0005,0.0008) 0.566619$ & $-0.0001(-0.0007,0.0006) 0.870392$ & $0.0006(-0.0001,0.0013) 0.104112$ \\
\hline & $50 \leq$ Aged $<60$ & $-0.0012(-0.0021,-0.0004) 0.005873$ & $-0.0017(-0.0025,-0.0008) 0.000156$ & $-0.0007(-0.0017,0.0002) 0.144140$ \\
\hline & $60 \leq$ Aged & $-0.0003(-0.0011,0.0006) 0.513681$ & $-0.0005(-0.0013,0.0004) 0.272575$ & $-0.0002(-0.0011,0.0007) 0.668748$ \\
\hline \multirow[t]{3}{*}{ L4 BMD } & $20 \leq$ Aged $<30$ & $-0.0003(-0.0009,0.0004) 0.413254$ & $-0.0005(-0.0012,0.0001) 0.124521$ & $0.0000(-0.0007,0.0007) 0.999632$ \\
\hline & $30 \leq$ Aged $<40$ & $-0.0006(-0.0012,0.0001) 0.084888$ & $-0.0006(-0.0013,-0.0000) 0.045006$ & $-0.0001(-0.0008,0.0006) 0.741328$ \\
\hline & $40 \leq$ Aged $<50$ & $0.0001(-0.0005,0.0008) 0.679172$ & $-0.0001(-0.0008,0.0005) 0.722415$ & $0.0007(-0.0000,0.0014) 0.058517$ \\
\hline
\end{tabular}


Table 5 Association between HDL-C and BMD in males (Continued)

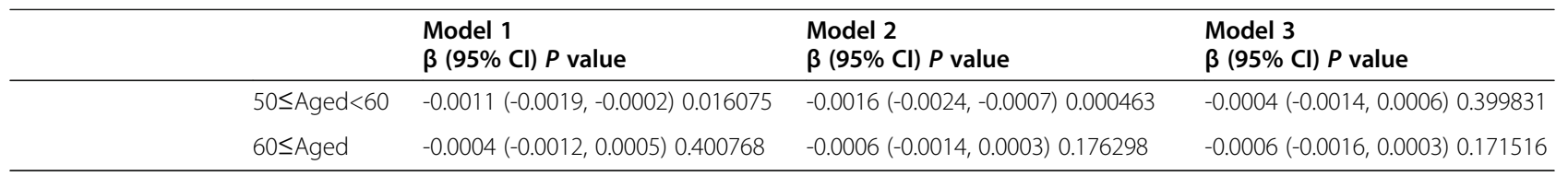

Model 1: no covariates were adjusted. Model 2: race/ethnicity (Mexican American; other Hispanic; non-Hispanic white; non-Hispanic black; other races) were adjusted. Model 3: race/ethnicity (Mexican American; other Hispanic; non-Hispanic white; non-Hispanic black; other races), education level (under high school; high school or equivalent; above high school), income to poverty ratio (quartile groups), BMl (obese, overweight, normal), smoking status (less than 100 cigarettes; greater than or equal to 100 cigarettes), alcohol consumption status (had at least 12 alcohol drinks past one year; have less than 12 alcohol drinks past one year), hypertension (yes; no), diabetes (yes; no; borderline), ALT (quartile groups), AST (quartile groups), total calcium (quartile groups), cholesterol (quartile groups), and C-reactive protein (quartile groups) were adjusted. HDL-C high-density lipoprotein cholesterol; BMD bone mineral density; $A L T$ alanine aminotransferase; $A S T$ aspartate aminotransferase

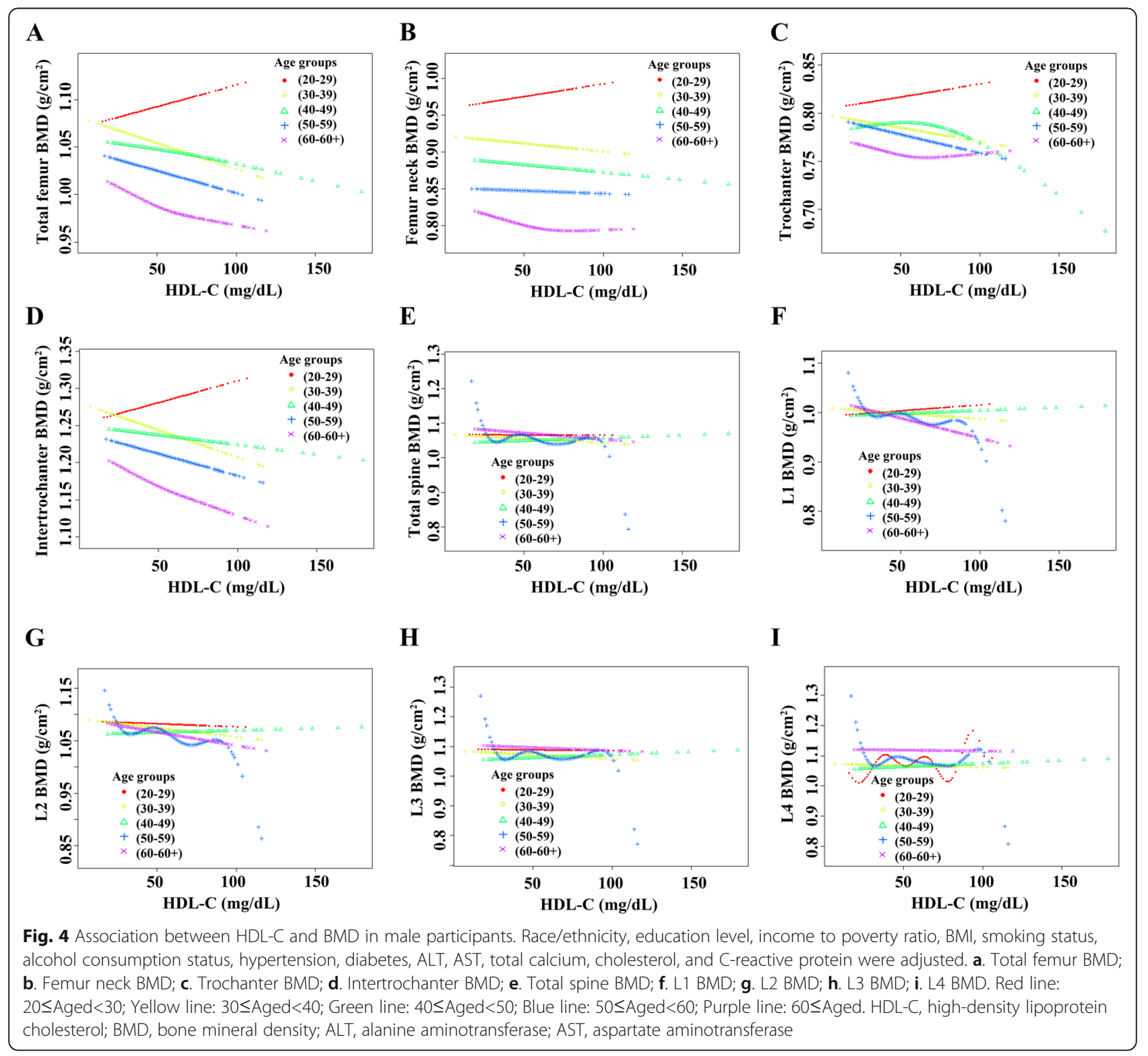


Table 6 Association between HDL-C and BMD in females

\begin{tabular}{|c|c|c|c|c|}
\hline & & $\begin{array}{l}\text { Model } 1 \\
\beta(95 \% \mathrm{Cl}) P \text { value }\end{array}$ & $\begin{array}{l}\text { Model } 2 \\
\beta(95 \% \mathrm{Cl}) P \text { value }\end{array}$ & $\begin{array}{l}\text { Model } 3 \\
\beta(95 \% \mathrm{Cl}) P \text { value }\end{array}$ \\
\hline \multirow[t]{5}{*}{ Total femur BMD } & $20 \leq$ Aged $<30$ & $-0.0009(-0.0014,-0.0003) 0.004084$ & $-0.0009(-0.0014,-0.0003) 0.003038$ & $-0.0000(-0.0007,0.0006) 0.895165$ \\
\hline & $30 \leq$ Aged $<40$ & $-0.0016(-0.0022,-0.0010)<0.000001$ & $-0.0017(-0.0023,-0.0011)<0.000001$ & $-0.0010(-0.0017,-0.0004) 0.002143$ \\
\hline & $40 \leq$ Aged $<50$ & $-0.0013(-0.0018,-0.0008)<0.000001$ & $-0.0013(-0.0018,-0.0008)<0.000001$ & $-0.0005(-0.0010,0.0001) 0.089961$ \\
\hline & $50 \leq$ Aged $<60$ & $-0.0020(-0.0027,-0.0013)<0.000001$ & $-0.0021(-0.0028,-0.0014)<0.000001$ & $-0.0010(-0.0018,-0.0002) 0.013817$ \\
\hline & $60 \leq$ Aged & $-0.0009(-0.0018,-0.0001) 0.027771$ & $-0.0011(-0.0019,-0.0003) 0.007503$ & $0.0000(-0.0009,0.0009) 0.965459$ \\
\hline \multirow[t]{5}{*}{ Femur neck BMD } & $20 \leq$ Aged $<30$ & $-0.0008(-0.0014,-0.0002) 0.012262$ & $-0.0008(-0.0014,-0.0002) 0.008148$ & $0.0002(-0.0005,0.0008) 0.613585$ \\
\hline & $30 \leq$ Aged $<40$ & $-0.0014(-0.0020,-0.0008) 0.000005$ & $-0.0015(-0.0021,-0.0009) 0.000001$ & $-0.0009(-0.0016,-0.0003) 0.005558$ \\
\hline & $40 \leq$ Aged $<50$ & $-0.0012(-0.0017,-0.0007) 0.000001$ & $-0.0012(-0.0017,-0.0007)<0.000001$ & $-0.0004(-0.0009,0.0001) 0.127233$ \\
\hline & $50 \leq$ Aged $<60$ & $-0.0020(-0.0027,-0.0014)<0.000001$ & $-0.0021(-0.0027,-0.0014)<0.000001$ & $-0.0010(-0.0018,-0.0003) 0.007700$ \\
\hline & $60 \leq$ Aged & $-0.0009(-0.0016,-0.0002) 0.018292$ & $-0.0011(-0.0018,-0.0004) 0.002431$ & $-0.0001(-0.0008,0.0007) 0.863724$ \\
\hline \multirow[t]{5}{*}{ Trochanter BMD } & $20 \leq$ Aged $<30$ & $-0.0006(-0.0011,-0.0001) 0.014098$ & $-0.0006(-0.0011,-0.0002) 0.010771$ & $-0.0001(-0.0007,0.0004) 0.610232$ \\
\hline & $30 \leq$ Aged $<40$ & $-0.0011(-0.0016,-0.0006) 0.000040$ & $-0.0012(-0.0017,-0.0006) 0.000016$ & $-0.0007(-0.0013,-0.0002) 0.012737$ \\
\hline & $40 \leq$ Aged $<50$ & $-0.0009(-0.0013,-0.0004) 0.000066$ & $-0.0009(-0.0013,-0.0005) 0.000031$ & $-0.0004(-0.0008,0.0001) 0.142166$ \\
\hline & $50 \leq$ Aged $<60$ & $-0.0014(-0.0020,-0.0008) 0.000003$ & $-0.0015(-0.0021,-0.0009) 0.000001$ & $-0.0007(-0.0014,-0.0001) 0.030223$ \\
\hline & $60 \leq$ Aged & $-0.0005(-0.0012,0.0002) 0.157187$ & $-0.0007(-0.0014,0.0000) 0.057321$ & $0.0002(-0.0006,0.0009) 0.642347$ \\
\hline \multirow[t]{5}{*}{ Intertrochanter BMD } & $20 \leq$ Aged $<30$ & $-0.0010(-0.0017,-0.0004) 0.002288$ & $-0.0010(-0.0017,-0.0004) 0.001898$ & $-0.0001(-0.0009,0.0006) 0.726263$ \\
\hline & $30 \leq$ Aged $<40$ & $-0.0019(-0.0026,-0.0012)<0.000001$ & $-0.0019(-0.0026,-0.0012)<0.000001$ & $-0.0012(-0.0019,-0.0004) 0.002305$ \\
\hline & $40 \leq$ Aged $<50$ & $-0.0016(-0.0022,-0.0010)<0.000001$ & $-0.0016(-0.0021,-0.0010)<0.000001$ & $-0.0005(-0.0012,0.0001) 0.128057$ \\
\hline & $50 \leq$ Aged $<60$ & $-0.0024(-0.0032,-0.0016)<0.000001$ & $-0.0024(-0.0033,-0.0016)<0.000001$ & $-0.0012(-0.0021,-0.0002) 0.016133$ \\
\hline & $60 \leq$ Aged & $-0.0012(-0.0023,-0.0002) 0.015602$ & $-0.0014(-0.0025,-0.0004) 0.004826$ & $-0.0001(-0.0011,0.0010) 0.910292$ \\
\hline \multirow[t]{5}{*}{ Total spine BMD } & $20 \leq$ Aged $<30$ & $-0.0009(-0.0015,-0.0004) 0.000976$ & $-0.0010(-0.0016,-0.0005) 0.000235$ & $-0.0004(-0.0010,0.0002) 0.217578$ \\
\hline & $30 \leq$ Aged $<40$ & $-0.0011(-0.0016,-0.0005) 0.000251$ & $-0.0012(-0.0017,-0.0006) 0.000042$ & $-0.0010(-0.0017,-0.0004) 0.001201$ \\
\hline & $40 \leq$ Aged $<50$ & $-0.0009(-0.0014,-0.0004) 0.000360$ & $-0.0011(-0.0016,-0.0006) 0.000042$ & $-0.0005(-0.0011,0.0001) 0.100247$ \\
\hline & $50 \leq$ Aged $<60$ & $-0.0020(-0.0028,-0.0012) 0.000001$ & $-0.0021(-0.0029,-0.0013)<0.000001$ & $-0.0012(-0.0021,-0.0002) 0.016337$ \\
\hline & $60 \leq$ Aged & $-0.0010(-0.0019,-0.0001) 0.035685$ & $-0.0013(-0.0022,-0.0004) 0.004202$ & $-0.0003(-0.0013,0.0006) 0.498599$ \\
\hline \multirow[t]{5}{*}{ L1 BMD } & $20 \leq$ Aged $<30$ & $-0.0009(-0.0015,-0.0003) 0.004548$ & $-0.0010(-0.0015,-0.0004) 0.001433$ & $-0.0002(-0.0008,0.0005) 0.640539$ \\
\hline & $30 \leq$ Aged $<40$ & $-0.0014(-0.0020,-0.0008) 0.000012$ & $-0.0015(-0.0021,-0.0009) 0.000003$ & $-0.0012(-0.0019,-0.0005) 0.000460$ \\
\hline & $40 \leq$ Aged $<50$ & $-0.0012(-0.0018,-0.0007) 0.000004$ & $-0.0013(-0.0019,-0.0008)<0.000001$ & $-0.0007(-0.0013,-0.0001) 0.015151$ \\
\hline & $50 \leq$ Aged $<60$ & $-0.0024(-0.0032,-0.0016)<0.000001$ & $-0.0025(-0.0033,-0.0017)<0.000001$ & $-0.0015(-0.0025,-0.0006) 0.002117$ \\
\hline & $60 \leq$ Aged & $-0.0014(-0.0023,-0.0005) 0.002435$ & $-0.0017(-0.0026,-0.0008) 0.000241$ & $-0.0006(-0.0016,0.0004) 0.234842$ \\
\hline \multirow[t]{5}{*}{ L2 BMD } & $20 \leq$ Aged $<30$ & $-0.0010(-0.0015,-0.0004) 0.001734$ & $-0.0010(-0.0016,-0.0004) 0.000554$ & $-0.0003(-0.0009,0.0004) 0.387438$ \\
\hline & $30 \leq$ Aged $<40$ & $-0.0013(-0.0019,-0.0007) 0.000043$ & $-0.0014(-0.0020,-0.0008) 0.000007$ & $-0.0012(-0.0019,-0.0005) 0.000458$ \\
\hline & $40 \leq$ Aged $<50$ & $-0.0011(-0.0016,-0.0005) 0.000098$ & $-0.0012(-0.0018,-0.0007) 0.000008$ & $-0.0006(-0.0012,0.0000) 0.061290$ \\
\hline & $50 \leq$ Aged $<60$ & $-0.0020(-0.0029,-0.0011) 0.000007$ & $-0.0021(-0.0030,-0.0013) 0.000002$ & $-0.0012(-0.0023,-0.0002) 0.022824$ \\
\hline & $60 \leq$ Aged & $-0.0012(-0.0022,-0.0003) 0.011340$ & $-0.0016(-0.0025,-0.0006) 0.001075$ & $-0.0007(-0.0017,0.0003) 0.193459$ \\
\hline \multirow[t]{5}{*}{ L3 BMD } & $20 \leq$ Aged $<30$ & $-0.0009(-0.0015,-0.0003) 0.001976$ & $-0.0010(-0.0016,-0.0005) 0.000412$ & $-0.0004(-0.0010,0.0003) 0.255710$ \\
\hline & $30 \leq$ Aged $<40$ & $-0.0009(-0.0015,-0.0003) 0.002536$ & $-0.0011(-0.0016,-0.0005) 0.000496$ & $-0.0010(-0.0017,-0.0003) 0.003036$ \\
\hline & $40 \leq$ Aged $<50$ & $-0.0007(-0.0012,-0.0001) 0.016616$ & $-0.0008(-0.0013,-0.0003) 0.003383$ & $-0.0003(-0.0009,0.0003) 0.335752$ \\
\hline & $50 \leq$ Aged $<60$ & $-0.0021(-0.0030,-0.0013) 0.000002$ & $-0.0022(-0.0031,-0.0014)<0.000001$ & $-0.0013(-0.0024,-0.0003) 0.012235$ \\
\hline & $60 \leq$ Aged & $-0.0010(-0.0020,-0.0000) 0.042502$ & $-0.0013(-0.0023,-0.0004) 0.005913$ & $-0.0003(-0.0014,0.0007) 0.548696$ \\
\hline \multirow[t]{5}{*}{ L4 BMD } & $20 \leq$ Aged $<30$ & $-0.0009(-0.0015,-0.0004) 0.001136$ & $-0.0010(-0.0016,-0.0004) 0.000418$ & $-0.0006(-0.0013,0.0000) 0.052108$ \\
\hline & $30 \leq$ Aged $<40$ & $-0.0008(-0.0014,-0.0002) 0.009702$ & $-0.0009(-0.0015,-0.0003) 0.002916$ & $-0.0008(-0.0014,-0.0001) 0.018291$ \\
\hline & $40 \leq$ Aged $<50$ & $-0.0008(-0.0014,-0.0003) 0.002988$ & $-0.0010(-0.0015,-0.0004) 0.000560$ & $-0.0004(-0.0010,0.0002) 0.220609$ \\
\hline & $50 \leq$ Aged $<60$ & $-0.0016(-0.0024,-0.0008) 0.000145$ & $-0.0017(-0.0025,-0.0009) 0.000041$ & $-0.0008(-0.0018,0.0002) 0.108678$ \\
\hline & $60 \leq$ Aged & $-0.0006(-0.0016,0.0004) 0.235832$ & $-0.0009(-0.0019,0.0000) 0.053248$ & $-0.0001(-0.0011,0.0010) 0.884132$ \\
\hline
\end{tabular}

Model 1: no covariates were adjusted. Model 2: race/ethnicity (Mexican American; other Hispanic; non-Hispanic white; non-Hispanic black; other races) were adjusted. Model 3: race/ethnicity (Mexican American; other Hispanic; non-Hispanic white; non-Hispanic black; other races), education level (under high school; high school or equivalent; above high school), income to poverty ratio (quartile groups), BMI (obese, overweight, normal), smoking status (less than 100 cigarettes; greater than or equal to 100 cigarettes), alcohol consumption status (had at least 12 alcohol drinks past one year; have less than 12 alcohol drinks past one year), hypertension (yes; no), diabetes (yes; no; borderline), ALT (quartile groups), AST (quartile groups), total calcium (quartile groups), cholesterol (quartile groups), and C-reactive protein (quartile groups) were adjusted. $H D L-C$ highdensity lipoprotein cholesterol; BMD bone mineral density; $A L T$ alanine aminotransferase; $A S T$ aspartate aminotransferase 
Table 7 Two-piecewise linear regression models of HDL-C on bone mineral density in females

\begin{tabular}{|c|c|c|c|c|c|}
\hline $\begin{array}{l}\text { Age } \\
\text { Groups }\end{array}$ & & Index & & & \\
\hline \multirow{7}{*}{$\begin{array}{l}20 \leq \text { Aged }< \\
30\end{array}$} & & Total femur BMD & Femur neck BMD & Trochanter BMD & Intertrochanter BMD \\
\hline & $\begin{array}{l}\text { Fitting by the standard linear } \\
\text { model }\end{array}$ & $\begin{array}{l}-0.0000(-0.0007,0.0006) \\
0.8952\end{array}$ & $\begin{array}{l}0.0002(-0.0005,0.0008) \\
0.6136\end{array}$ & $\begin{array}{l}-0.0001(-0.0007,0.0004) \\
0.6102\end{array}$ & $\begin{array}{l}-0.0001(-0.0009,0.0006) \\
0.7263\end{array}$ \\
\hline & $\begin{array}{l}\text { Fitting by the two-piecewise } \\
\text { linear model }\end{array}$ & & & & \\
\hline & Inflection point (mg/dL) & 65 & 65 & 65 & 65 \\
\hline & HDL-C $<$ Infection point & $\begin{array}{l}-0.0011(-0.0021 \\
-0.0001) 0.0257\end{array}$ & $\begin{array}{l}-0.0006(-0.0016,0.0004) \\
0.2539\end{array}$ & $\begin{array}{l}-0.0011(-0.0019,-0.0002) \\
0.0141\end{array}$ & $\begin{array}{l}-0.0013(-0.0024,-0.0002) \\
0.0228\end{array}$ \\
\hline & HDL-C > Infection point & $\begin{array}{l}0.0016(0.0003,0.0028) \\
0.0170\end{array}$ & $\begin{array}{l}0.0013(-0.0000,0.0026) \\
0.0549\end{array}$ & $\begin{array}{l}0.0013(0.0001,0.0024) \\
0.0291\end{array}$ & $\begin{array}{l}0.0016(0.0002,0.0031) \\
0.0298\end{array}$ \\
\hline & Log likelihood ratio & 0.004 & 0.05 & 0.004 & 0.006 \\
\hline \multirow{7}{*}{$\begin{array}{l}30 \leq \text { Aged }< \\
40\end{array}$} & & Total femur BMD & Femur neck BMD & Trochanter BMD & Intertrochanter BMD \\
\hline & $\begin{array}{l}\text { Fitting by the standard linear } \\
\text { model }\end{array}$ & $\begin{array}{l}-0.0010(-0.0017 \\
-0.0004) 0.0021\end{array}$ & $\begin{array}{l}-0.0009(-0.0016 \\
-0.0003) 0.0056\end{array}$ & $\begin{array}{l}-0.0007(-0.0013,-0.0002) \\
0.0127\end{array}$ & $\begin{array}{l}-0.0012(-0.0019,-0.0004) \\
0.0023\end{array}$ \\
\hline & $\begin{array}{l}\text { Fitting by the two-piecewise } \\
\text { linear model }\end{array}$ & & & & \\
\hline & Inflection point (mg/dL) & 45 & 45 & 45 & 45 \\
\hline & $\mathrm{HDL}-\mathrm{C}<$ Infection point & $\begin{array}{l}0.0021(-0.0007,0.0048) \\
0.1389\end{array}$ & $\begin{array}{l}0.0013(-0.0014,0.0041) \\
0.3443\end{array}$ & $\begin{array}{l}0.0018(-0.0006,0.0043) \\
0.1444\end{array}$ & $\begin{array}{l}0.0030(-0.0002,0.0062) \\
0.0626\end{array}$ \\
\hline & HDL-C > Infection point & $\begin{array}{l}-0.0015(-0.0023 \\
-0.0007) 0.0001\end{array}$ & $\begin{array}{l}-0.0013(-0.0020 \\
-0.0005) 0.0013\end{array}$ & $\begin{array}{l}-0.0012(-0.0018,-0.0005) \\
0.0012\end{array}$ & $\begin{array}{l}-0.0018(-0.0027,-0.0009) \\
<0.0001\end{array}$ \\
\hline & Log likelihood ratio & 0.02 & 0.092 & 0.031 & 0.007 \\
\hline \multirow{14}{*}{$\begin{array}{l}50 \leq \text { Aged }< \\
60\end{array}$} & & Total femur BMD & Femur neck BMD & Trochanter BMD & Intertrochanter BMD \\
\hline & $\begin{array}{l}\text { Fitting by the standard linear } \\
\text { model }\end{array}$ & $\begin{array}{l}-0.0010(-0.0018 \\
-0.0002) 0.0138\end{array}$ & $\begin{array}{l}-0.0010(-0.0018 \\
-0.0003) 0.0077\end{array}$ & $\begin{array}{l}-0.0007(-0.0014,-0.0001) \\
0.0302\end{array}$ & $\begin{array}{l}-0.0012(-0.0021,-0.0002) \\
0.0161\end{array}$ \\
\hline & $\begin{array}{l}\text { Fitting by the two-piecewise } \\
\text { linear model }\end{array}$ & & & & \\
\hline & Inflection point (mg/dL) & 70 & 70 & 70 & 70 \\
\hline & HDL-C $<$ Infection point & $\begin{array}{l}-0.0025(-0.0037 \\
-0.0012) 0.0002\end{array}$ & $\begin{array}{l}-0.0017(-0.0030 \\
-0.0005) 0.0073\end{array}$ & $\begin{array}{l}-0.0015(-0.0026,-0.0004) \\
0.0085\end{array}$ & $\begin{array}{l}-0.0032(-0.0047,-0.0017) \\
<0.0001\end{array}$ \\
\hline & HDL-C > Infection point & $\begin{array}{l}0.0008(-0.0007,0.0022) \\
0.2960\end{array}$ & $\begin{array}{l}-0.0002(-0.0016,0.0012) \\
0.7467\end{array}$ & $\begin{array}{l}0.0001(-0.0011,0.0014) \\
0.8311\end{array}$ & $\begin{array}{l}0.0013(-0.0004,0.0030) \\
0.1407\end{array}$ \\
\hline & Log likelihood ratio & 0.003 & 0.161 & 0.084 & $<0.001$ \\
\hline & & L1 BMD & L2 BMD & L3 BMD & L4 BMD \\
\hline & $\begin{array}{l}\text { Fitting by the standard linear } \\
\text { model }\end{array}$ & $\begin{array}{l}-0.0015(-0.0025 \\
-0.0006) 0.0021\end{array}$ & $\begin{array}{l}-0.0012(-0.0023 \\
-0.0002) 0.0228\end{array}$ & $\begin{array}{l}-0.0013(-0.0024,-0.0003) \\
0.0122\end{array}$ & $\begin{array}{l}-0.0008(-0.0018,0.0002) \\
0.1087\end{array}$ \\
\hline & $\begin{array}{l}\text { Fitting by the two-piecewise } \\
\text { linear model }\end{array}$ & & & & \\
\hline & Inflection point (mg/dL) & 70 & 70 & 70 & 70 \\
\hline & HDL-C $<$ Infection point & $\begin{array}{l}-0.0029(-0.0044 \\
-0.0013) 0.0004\end{array}$ & $\begin{array}{l}-0.0030(-0.0047 \\
-0.0013) 0.0006\end{array}$ & $\begin{array}{l}-0.0035(-0.0052,-0.0018) \\
<0.0001\end{array}$ & $\begin{array}{l}-0.0025(-0.0041,-0.0009) \\
0.0023\end{array}$ \\
\hline & HDL-C > Infection point & $\begin{array}{l}0.0001(-0.0016,0.0019) \\
0.8969\end{array}$ & $\begin{array}{l}0.0009(-0.0010,0.0028) \\
0.3502\end{array}$ & $\begin{array}{l}0.0013(-0.0006,0.0031) \\
0.1889\end{array}$ & $\begin{array}{l}0.0012(-0.0006,0.0030) \\
0.1869\end{array}$ \\
\hline & Log likelihood ratio & 0.025 & 0.007 & $<0.001$ & 0.007 \\
\hline \multirow[t]{4}{*}{$60 \leq$ Aged } & & Total femur BMD & Femur neck BMD & Trochanter BMD & Intertrochanter BMD \\
\hline & $\begin{array}{l}\text { Fitting by the standard linear } \\
\text { model }\end{array}$ & $\begin{array}{l}0.0000(-0.0009,0.0009) \\
0.9655\end{array}$ & $\begin{array}{l}-0.0001(-0.0008,0.0007) \\
0.8637\end{array}$ & $\begin{array}{l}0.0002(-0.0006,0.0009) \\
0.6423\end{array}$ & $\begin{array}{l}-0.0001(-0.0011,0.0010) \\
0.9103\end{array}$ \\
\hline & $\begin{array}{l}\text { Fitting by the two-piecewise } \\
\text { linear model }\end{array}$ & & & & \\
\hline & Inflection point (mg/dL) & 45 & 45 & 45 & 45 \\
\hline
\end{tabular}


Table 7 Two-piecewise linear regression models of HDL-C on bone mineral density in females (Continued)

\begin{tabular}{|c|c|c|c|c|c|}
\hline $\begin{array}{l}\text { Age } \\
\text { Groups }\end{array}$ & & \multicolumn{4}{|l|}{ Index } \\
\hline & $\mathrm{HDL}-\mathrm{C}<$ Infection point & $\begin{array}{l}0.0076(0.0031,0.0121) \\
0.0010\end{array}$ & $\begin{array}{l}0.0056(0.0017,0.0095) \\
0.0050\end{array}$ & $\begin{array}{l}0.0055(0.0017,0.0094) \\
0.0052\end{array}$ & $\begin{array}{l}0.0096(0.0041,0.0151) \\
0.0007\end{array}$ \\
\hline & HDL-C > Infection point & $\begin{array}{l}-0.0008(-0.0018,0.0002) \\
0.1095\end{array}$ & $\begin{array}{l}-0.0007(-0.0015,0.0002) \\
0.1171\end{array}$ & $\begin{array}{l}-0.0004(-0.0013,0.0004) \\
0.3462\end{array}$ & $\begin{array}{l}-0.0011(-0.0023,0.0001) \\
0.0716\end{array}$ \\
\hline & Log likelihood ratio & $<0.001$ & 0.003 & 0.004 & $<0.001$ \\
\hline
\end{tabular}

Race/ethnicity (Mexican American; other Hispanic; non-Hispanic white; non-Hispanic black; other races), education level (under high school; high school or equivalent; above high school), income to poverty ratio (quartile groups), BMI (obese, overweight, normal), smoking status (less than 100 cigarettes; greater than or equal to 100 cigarettes), alcohol consumption status (had at least 12 alcohol drinks past one year; have less than 12 alcohol drinks past one year), hypertension (yes; no), diabetes (yes; no; borderline), ALT (quartile groups), AST (quartile groups), total calcium (quartile groups), cholesterol (quartile groups), and C-reactive protein (quartile groups) were adjusted. $H D L-C$ high-density lipoprotein cholesterol; BMD bone mineral density; $A L T$ alanine aminotransferase; $A S T$ aspartate aminotransferase

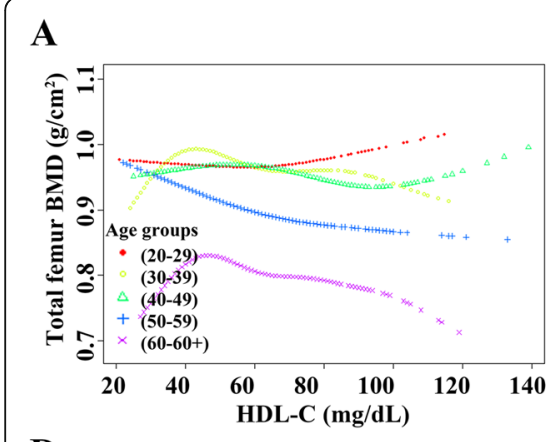

D

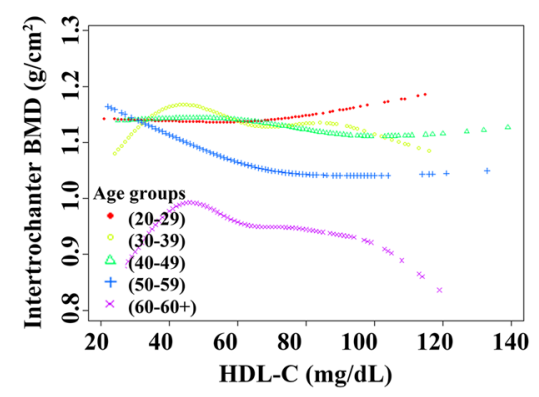

G

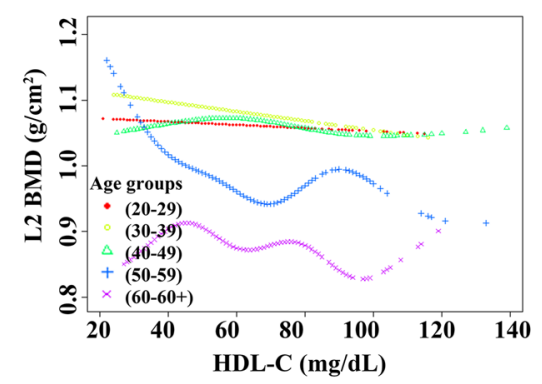

B

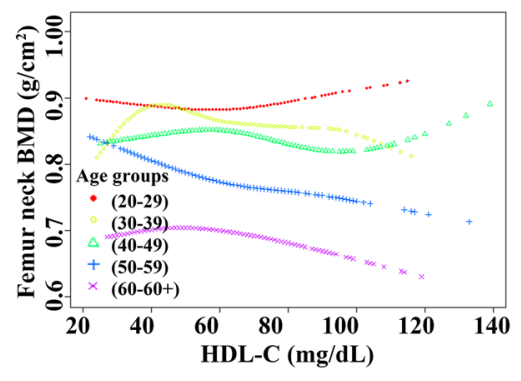

$\mathbf{E}$

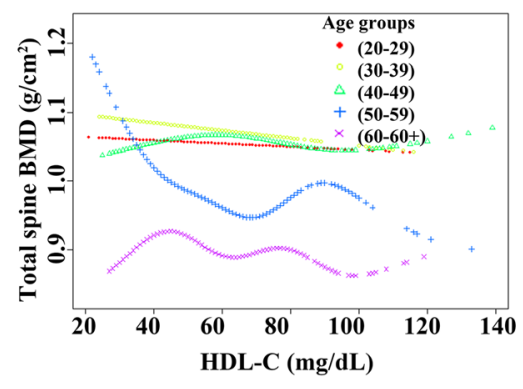

$\mathbf{H}$

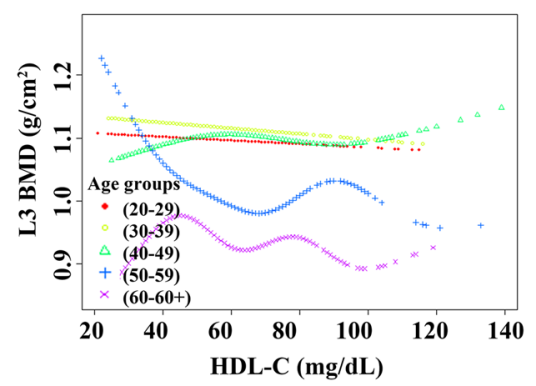

C

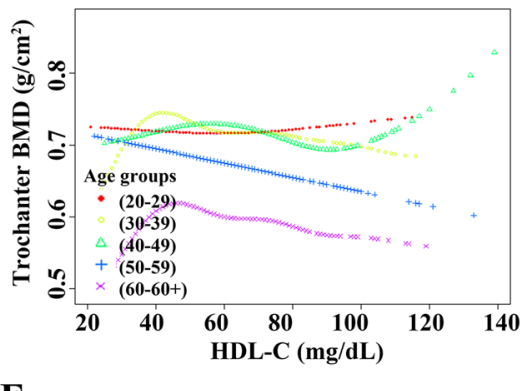

F

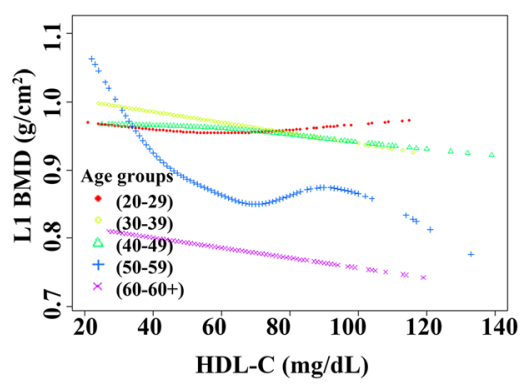

I

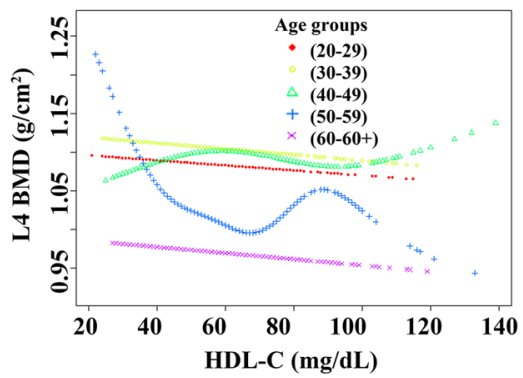

Fig. 5 Association between HDL-C and BMD in female participants. Race/ethnicity, education level, income to poverty ratio, BMI, smoking status, alcohol consumption status, hypertension, diabetes, ALT, AST, total calcium, cholesterol, and C-reactive protein were adjusted. a. Total femur BMD; b. Femur neck BMD; c. Trochanter BMD; d. Intertrochanter BMD; e. Total spine BMD; f. L1 BMD; g. L2 BMD; h. L3 BMD; i. L4 BMD. Red line:

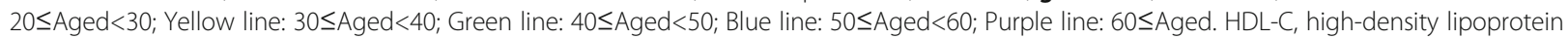
cholesterol; BMD, bone mineral density; ALT, alanine aminotransferase; AST, aspartate aminotransferase 
Table 8 Associations between HDL-C and osteopenia or osteoporosis in females

\begin{tabular}{|c|c|c|c|c|c|c|}
\hline & Age (20-29) & Age (30-39) & Age (40-49) & Age (50-59) & Age (60-) & Total \\
\hline \multicolumn{7}{|l|}{ Non-adjusted } \\
\hline $\begin{array}{l}\mathrm{HDL}(49-61 \\
\mathrm{mg} / \mathrm{dL})\end{array}$ & Reference & Reference & Reference & Reference & Reference & Reference \\
\hline $\begin{array}{l}\mathrm{HDL}(21-48 \\
\mathrm{mg} / \mathrm{dL})\end{array}$ & $\begin{array}{l}0.9387(0.5986 \\
1.4718) 0.782692\end{array}$ & $\begin{array}{l}0.5797(0.3550 \\
0.9466) 0.029321\end{array}$ & $\begin{array}{l}1.9966(1.2513 \\
3.1860) 0.003729\end{array}$ & $\begin{array}{l}0.9575(0.5839 \\
1.5700) 0.863251\end{array}$ & $\begin{array}{l}0.8372(0.5043 \\
1.3900) 0.492132\end{array}$ & $\begin{array}{l}0.9872(0.7972 \\
1.2224) 0.905687\end{array}$ \\
\hline $\begin{array}{l}\mathrm{HDL}(62-139 \\
\mathrm{mg} / \mathrm{dL})\end{array}$ & $\begin{array}{l}1.0672(0.6872 \\
1.6575) 0.772075\end{array}$ & $\begin{array}{l}1.3464(0.8806 \\
2.0587) 0.169779\end{array}$ & $\begin{array}{l}2.5978(1.6734 \\
4.0328) 0.000021\end{array}$ & $\begin{array}{l}2.7259(1.6882 \\
4.4014) 0.000041\end{array}$ & $\begin{array}{l}1.5604(0.9488 \\
2.5663) 0.079599\end{array}$ & $\begin{array}{l}1.7096(1.4004 \\
2.0869)<0.000001\end{array}$ \\
\hline \multicolumn{7}{|l|}{ Adjusted } \\
\hline $\begin{array}{l}\mathrm{HDL}(49-61 \\
\mathrm{mg} / \mathrm{dL})\end{array}$ & Reference & Reference & Reference & Reference & Reference & Reference \\
\hline $\begin{array}{l}\mathrm{HDL}(21-48 \\
\mathrm{mg} / \mathrm{dL})\end{array}$ & $\begin{array}{l}1.2054(0.7176 \\
2.0251) 0.480194\end{array}$ & $\begin{array}{l}0.6875(0.3996 \\
1.1829) 0.175989\end{array}$ & $\begin{array}{l}2.4873(1.4866 \\
4.1618) 0.000521\end{array}$ & $\begin{array}{l}1.0997(0.6186 \\
1.9549) 0.746046\end{array}$ & $\begin{array}{l}1.1149(0.5826 \\
2.1335) 0.742546\end{array}$ & $\begin{array}{l}1.1529(0.9135 \\
1.4550) 0.230883\end{array}$ \\
\hline $\begin{array}{l}\mathrm{HDL}(62-139 \\
\mathrm{mg} / \mathrm{dL})\end{array}$ & $\begin{array}{l}0.9365(0.5670 \\
1.5466) 0.797616\end{array}$ & $\begin{array}{l}1.1742(0.7322 \\
1.8830) 0.505203\end{array}$ & $\begin{array}{l}2.0781(1.2673 \\
3.4075) 0.003744\end{array}$ & $\begin{array}{l}2.3301(1.3215 \\
4.1085) 0.003463\end{array}$ & $\begin{array}{l}1.5008(0.7983 \\
2.8214) 0.207419\end{array}$ & $\begin{array}{l}1.3831(1.1118 \\
1.7207) 0.003602\end{array}$ \\
\hline
\end{tabular}

Race/ethnicity (Mexican American; other Hispanic; non-Hispanic white; non-Hispanic black; other races), education level (under high school; high school or equivalent; above high school), income to poverty ratio (quartile groups), BMI (obese, overweight, normal), smoking status (less than 100 cigarettes; greater than or equal to 100 cigarettes), alcohol consumption status (had at least 12 alcohol drinks past one year; have less than 12 alcohol drinks past one year), hypertension (yes; no), diabetes (yes; no; borderline), ALT (quartile groups), AST (quartile groups), total calcium (quartile groups), cholesterol (quartile groups), and C-reactive protein (quartile groups) were adjusted. $H D L-C$, high-density lipoprotein cholesterol; $A L T$ alanine aminotransferase; $A S T$ aspartate aminotransferase

\section{Conclusion}

This study demonstrated that HDL-C levels exhibit an inverse correlation with BMD. Especially in females, clinicians need to be alert to patients with high HDL-C levels, which may indicate an increased risk of osteoporosis or osteopenia. For these patients, close monitoring of BMD and early intervention may be necessary.

\section{Supplementary Information}

The online version contains supplementary material available at https://doi. org/10.1186/s12944-021-01497-7.

Additional file 1: Table S1. Definition of osteoporosis and osteopenia.

\section{Acknowledgements}

This study was supported by the National Natural Science Foundation of China (81874017, 81960403 and 82060405); Natural Science Foundation of Gansu Province of China (20JR5RA320); Cuiying Scientific and Technological Innovation Program of Lanzhou University Second Hospital (CY2017-ZD02). At the same time, we would like to express our gratitude to American Journal Experts (https://www.aje.com/) for the language editing services provided.

\section{Authors' contributions}

YT and SW contributed equally to this work. YT and BG contributed the central idea, YT and SW analyzed most of the data. YT wrote the initial draft of the paper. The remaining authors contributed to refining the ideas, carrying out additional analyses and finalizing this paper. The author(s) read and approved the final manuscript.

\section{Funding}

This study was supported by the National Natural Science Foundation of China (81874017, 81960403 and 82060405); Natural Science Foundation of Gansu Province of China (20JR5RA320); Cuiying Scientific and Technological Innovation Program of Lanzhou University Second Hospital (CY2017-ZD02).

\section{Availability of data and materials}

The datasets obtained and analysed during the current study are available in the NHANES [https://www.cdc.gov/nchs/nhanes/index.htm].

\section{Declarations}

Ethics approval and consent to participate

All procedures performed in studies involving human participants were in accordance with the ethical standards of the institutional and/or national research committee and with the 1964 Helsinki declaration and its later amendments or comparable ethical standards. All analyses were based on data of the National Health and Nutrition Examination Survey (NHANES). The study was approved by the ethics review board of the National Center for Health Statistics. The National Center for Health Statistics Ethics Review Board protocol numbers are Protocol \#2005-06 (NHANES 2005-2006), Continuation of Protocol \#2005-06 (NHANES 2007-2008), Continuation of Protocol \#200506 (NHANES 2009-2010), respectively. The detailed information located on the NHANES website.

\section{Consent for publication}

Not applicable.

\section{Competing interests}

The authors declare that they have no conflict of interest.

\section{Author details}

'Department of Orthopaedics, Lanzhou University Second Hospital, \#82 Cuiyingmen, Lanzhou, Gansu, People's Republic of China 730000.

${ }^{2}$ Orthopaedics Key Laboratory of Gansu Province, Lanzhou, Gansu, China.

${ }^{3}$ Orthopaedic Clinical Research Center of Gansu Province, Lanzhou, Gansu, China.

Received: 21 May 2021 Accepted: 29 June 2021

Published online: 25 July 2021

\section{References}

1. Chiesa ST, Charakida M. High-Density Lipoprotein Function and Dysfunction in Health and Disease. Cardiovasc Drugs Ther. 2019;33:207-19.

2. Chapman MJ, Ginsberg HN, Amarenco P, Andreotti F, Borén J, Catapano AL, et al. Triglyceride-rich lipoproteins and high-density lipoprotein cholesterol in patients at high risk of cardiovascular disease: evidence and guidance for management. Eur Heart J. 2011;32:1345-61.

3. Chang TI, Streja E, Moradi H. Could high-density lipoprotein cholesterol predict increased cardiovascular risk? Curr Opin Endocrinol Diabetes Obes. 2017;24:140-7. 
4. Gordon DJ, Probstfield JL, Garrison RJ, Neaton JD, Castelli WP, Knoke JD, et al. High-density lipoprotein cholesterol and cardiovascular disease. Four prospective American studies. Circulation. 1989;79:8-15.

5. Rosenson RS. Low high-density lipoprotein cholesterol and cardiovascular disease: risk reduction with statin therapy. Am Heart J. 2006;151:556-63.

6. Madsen CM, Varbo A, Nordestgaard BG. Extreme high high-density lipoprotein cholesterol is paradoxically associated with high mortality in men and women: two prospective cohort studies. Eur Heart J. 2017;38: 2478-86.

7. Hamer M, O'Donovan G, Stamatakis E. High-Density Lipoprotein Cholesterol and Mortality: Too Much of a Good Thing? Arterioscler Thromb Vasc Biol. 2018;38:669-72.

8. Ensrud KE, Crandall CJ. Osteoporosis. Ann Intern Med. 2017;167:Itc17-itc32.

9. Wright NC, Looker AC, Saag KG, Curtis JR, Delzell ES, Randall S, et al. The recent prevalence of osteoporosis and low bone mass in the United States based on bone mineral density at the femoral neck or lumbar spine. J Bone Miner Res. 2014;29:2520-6.

10. Alejandro P, Constantinescu F. A Review of Osteoporosis in the Older Adult: An Update. Rheum Dis Clin North Am. 2018;44:437-51.

11. Nomura S, Kitami A, Takao-Kawabata R, Takakura A, Nakatsugawa M, Kono R, et al. Teriparatide Improves Bone and Lipid Metabolism in a Male Rat Model of Type 2 Diabetes Mellitus. Endocrinology. 2019;160:2339-52.

12. Gajewska J, Weker H, Ambroszkiewicz J, Szamotulska K, Chełchowska M, Franek $\mathrm{E}$, et al. Alterations in markers of bone metabolism and adipokines following a 3-month lifestyle intervention induced weight loss in obese prepubertal children. Exp Clin Endocrinol Diabetes. 2013;121:498-504.

13. Villareal DT, Shah K, Banks MR, Sinacore DR, Klein S. Effect of weight loss and exercise therapy on bone metabolism and mass in obese older adults: a one-year randomized controlled trial. J Clin Endocrinol Metab. 2008;93: 2181-7.

14. Tian L, Yu X. Lipid metabolism disorders and bone dysfunction--interrelated and mutually regulated (review). Mol Med Rep. 2015;12:783-94.

15. Li GH, Cheung CL, Au PC, Tan KC, Wong IC, Sham PC. Positive effects of low LDL-C and statins on bone mineral density: an integrated epidemiological observation analysis and Mendelian randomization study. Int J Epidemiol. 2020:49:1221-35.

16. Zheng J, Brion MJ, Kemp JP, Warrington NM, Borges MC, Hemani G, et al. The Effect of Plasma Lipids and Lipid-Lowering Interventions on Bone Mineral Density: A Mendelian Randomization Study. J Bone Miner Res. 2020; 35:1224-35.

17. Maghbooli Z, Khorrami-Nezhad L, Adabi E, Ramezani M, Asadollahpour E, Razi F, et al. Negative correlation of high-density lipoprotein-cholesterol and bone mineral density in postmenopausal Iranian women with vitamin D deficiency. Menopause. 2018;25:458-64.

18. Zhang Q, Zhou J, Wang Q, Lu C, Xu Y, Cao H, et al. Association between bone mineral density and lipid profile in chinese women. Clin Interv Aging. 2020;15:1649-64.

19. Cui LH, Shin MH, Chung EK, Lee YH, Kweon SS, Park KS, et al. Association between bone mineral densities and serum lipid profiles of pre- and postmenopausal rural women in South Korea. Osteoporos Int. 2005;16:1975-81.

20. Jeong IK, Cho SW, Kim SW, Choi HJ, Park KS, Kim SY, et al. Lipid profiles and bone mineral density in pre- and postmenopausal women in Korea. Calcif Tissue Int. 2010;87:507-12.

21. CDC (2005) National Health and Nutrition Examination Survey, NHANES 2005-2006. https://wwwn.cdc.gov/nchs/nhanes/ContinuousNhanes/Default.a spx?BeginYear=2005 Accessed 6 April 2021

22. CDC (2007) National Health and Nutrition Examination Survey, NHANES 2007-2008. https://wwwn.cdc.gov/nchs/nhanes/ContinuousNhanes/Default.a spx?BeginYear=2007 Accessed 6 April 2021

23. CDC (2009) National Health and Nutrition Examination Survey, NHANES 2009-2010. https://wwwn.cdc.gov/nchs/nhanes/ContinuousNhanes/Default.a spx?BeginYear=2009 Accessed 6 April 2021

24. CDC (2005) NHANES 2005-2006 Brochures and Consent Documents. https:// wwwn.cdc.gov/nchs/nhanes/ContinuousNhanes/Documents.aspx?BeginYea $r=2005$ Accessed 6 April 2021

25. CDC (2007) NHANES 2007-2008 Brochures and Consent Documents. https:// wwwn.cdc.gov/nchs/nhanes/ContinuousNhanes/Documents.aspx?BeginYea $r=2007$ Accessed 6 April 2021

26. CDC (2009) NHANES 2009-2010 Brochures and Consent Documents. https:// wwwn.cdc.gov/nchs/nhanes/ContinuousNhanes/Documents.aspx?BeginYea $r=2009$ Accessed 6 April 2021
27. CDC (2021) Module 3: Weighting. https://wwwn.cdc.gov/nchs/nhanes/ tutorials/module3.aspx Accessed 6 April 2021

28. CDC (2021) HDL-Cholesterol Description of Laboratory Methodology. https://wwwn.cdc.gov/Nchs/Nhanes/2005-2006/HDL_D.htm Accessed 6 April 2021

29. CDC (2021) Dual Energy X-ray Absorptiometry (DXA) Procedures Manual. https://wwwn.cdc.gov/nchs/data/nhanes/2007-2008/manuals/manual_dexa. pdf Accessed 6 April 2021

30. Looker AC, Orwoll ES, Johnston CC Jr, Lindsay RL, Wahner HW, Dunn WL, et al. Prevalence of low femoral bone density in older U.S. adults from NHANES III. J Bone Miner Res. 1997;12:1761-8.

31. Makovey J, Chen JS, Hayward C, Williams FM, Sambrook PN. Association between serum cholesterol and bone mineral density. Bone. 2009:44:208-13.

32. Mohamad NV, Soelaiman IN, Chin KY. A concise review of testosterone and bone health. Clin Interv Aging. 2016;11:1317-24.

33. Vanderschueren D, Vandenput L, Boonen S, Lindberg MK, Bouillon R, Ohlsson C. Androgens and bone. Endocr Rev. 2004;25:389-425.

34. Khosla S, Oursler MJ, Monroe DG. Estrogen and the skeleton. Trends Endocrinol Metab. 2012;23:576-81.

35. Semmens J, Rouse I, Beilin LJ, Masarei JR. Relationship of plasma HDLcholesterol to testosterone, estradiol, and sex-hormone-binding globulin levels in men and women. Metabolism. 1983:32:428-32.

36. Jirapinyo M, Theppisai U, Manonai J, Suchartwatnachai $C$, Jorgensen LN. Effect of combined oral estrogen/progestogen preparation (Kliogest) on bone mineral density, plasma lipids and postmenopausal symptoms in HRTnaïve Thai women. Acta Obstet Gynecol Scand. 2003:82:857-66.

37. Wang T, He C. TNF- $a$ and IL-6: The Link between Immune and Bone System. Curr Drug Targets. 2020;21:213-27.

38. Boyce BF. Advances in the regulation of osteoclasts and osteoclast functions. J Dent Res. 2013;92:860-7.

39. Mazidi M, Mikhailidis DP, Banach M. Associations between risk of overall mortality, cause-specific mortality and level of inflammatory factors with extremely low and high high-density lipoprotein cholesterol levels among American adults. Int J Cardiol. 2019;276:242-7.

40. Silbernagel G, Schöttker B, Appelbaum S, Scharnagl H, Kleber ME, Grammer TB, et al. High-density lipoprotein cholesterol, coronary artery disease, and cardiovascular mortality. Eur Heart J. 2013;34:3563-71.

41. Karlamangla AS, Singer BH, Reuben DB, Seeman TE. Increases in serum nonhigh-density lipoprotein cholesterol may be beneficial in some highfunctioning older adults: MacArthur studies of successful aging. J Am Geriatr Soc. 2004;52:487-94.

42. Voight BF, Peloso GM, Orho-Melander M, Frikke-Schmidt R, Barbalic M, Jensen MK, et al. Plasma HDL cholesterol and risk of myocardial infarction: a mendelian randomisation study. Lancet. 2012;380:572-80.

43. Huang YQ, Liu XC, Lo K, Liu L, Yu YL, Chen CL, et al. The U Shaped Relationship Between High-Density Lipoprotein Cholesterol and All-Cause or Cause-Specific Mortality in Adult Population. Clin Interv Aging. 2020;15: 1883-96.

44. Papachristou NI, Blair HC, Kalyvioti ES, Syggelos SA, Karavia EA, Kontogeorgakos $\mathrm{V}$, et al. Western-type diet differentially modulates osteoblast, osteoclast, and lipoblast differentiation and activation in a background of APOE deficiency. Lab Invest. 2018;98:1516-26.

45. Blair HC, Kalyvioti E, Papachristou NI, Tourkova IL, Syggelos SA, Deligianni D, et al. Apolipoprotein A-1 regulates osteoblast and lipoblast precursor cells in mice. Lab Invest. 2016:96:763-72.

\section{Publisher's Note}

Springer Nature remains neutral with regard to jurisdictional claims in published maps and institutional affiliations. 